\title{
Empleo y movilidad estructural. Trayectoria de un tema prebischiano
}

\section{Adolfo Gurrieri}

Ex Director,

División de Desarrollo Social,

Los decenios de 1980 y 1990 fueron prolíficos en absorción CEPAL

\section{Pedro Sáinz}

Ex Director, División de

Estadística y Proyecciones

Económicas,

CEPAL

psainz@eclac.cl

espuria de fuerza de trabajo en la mayoría de los países latinoamericanos, entendiendo por tal el rápido crecimiento de empleos de baja productividad. Esto constituyó un fuerte revés para las expectativas de reformas que perseguían internacionalizar las economías y situarlas en medios competitivos de alta productividad. Este artículo presenta la trayectoria de la absorción productiva de la fuerza de trabajo desde la posguerra. Rescata el valor de la categoría de análisis, considerada por el pensamiento cepalino como el nexo principal entre el progreso técnico en las actividades económicas y el mejoramiento de las condiciones de vida de la población, especialmente de los estratos pobres. Y muestra el valor de situar en el centro del análisis la heterogeneidad productiva latinoamericana, y las consecuencias del menguado crecimiento económico de las décadas de 1980 y 1990 y del tipo de transformación productiva sobre la movilidad social. 


\section{I}

\section{Introducción}

El virtual estancamiento de la economía latinoamericana en el quinquenio 1998-2002 ha incentivado las evaluaciones estructurales de las economías latinoamericanas. En particular, la constatación del escaso crecimiento de la productividad media de la fuerza de trabajo junto al masivo crecimiento de las ocupaciones de baja productividad o informales han puesto de relieve la vigencia de los enfoques cepalinos que asignan importancia a la absorción productiva y a la absorción espuria de la fuerza de trabajo. A la vez, existen fundadas dudas acerca del grado de movilidad social ascendente que se dio en los decenios de 1980 y 1990.

Este artículo tiene por objetivo principal presentar algunos antecedentes teóricos y empíricos acerca de la trayectoria de la absorción productiva de fuerza de trabajo y la movilidad estructural a partir de la posguerra, extraídos de algunos estudios realizados principalmente en la CEPAL que ponen en evidencia las raíces de la situación actual y el grado en que quienes postularon las reformas económicas e institucionales de las décadas de 1980 y 1990 subestimaron la magnitud del desafío de lograr la absorción productiva de la población económicamente activa (PEA) y sus efectos sobre la movilidad estructural.

El presente estudio también destaca la utilidad del pensamiento clásico de la CEPAL, tanto en sus primeras etapas como en la actualidad. El proceso de absorción productiva de la fuerza de trabajo - es decir, la elevación de su nivel de productividad - fue considerado el nexo principal entre el progreso técnico en las actividades económicas y el mejoramiento de las condiciones de vida de la población, en especial de los estratos pobres. Como muestran estudios recientes, la extraordinaria heterogeneidad del fenómeno de absorción en términos de productividad, que muchos postulados teóricos y programáticos no consideraron, tiene un notable poder para explicar la equidad y la pobreza. Medítese solamente en la proliferación de estudios que concentran su interés en la evolución del producto interno bruto (РІв) y la pobreza, suponiendo que tras esos agregados subyacen fenómenos relativamente homogéneos.

En el pensamiento cepalino la absorción lograda en un mercado del trabajo marcadamente heterogéneo es a la vez un objetivo principal del desarrollo económico y el mejor indicador de la evolución de ese de- sarrollo. Hasta la década de 1970 se le prestó una atención preferente en la CEPAL, la que hubo de ser sustituida por la preocupación por el corto plazo que impuso la crisis del decenio de 1980. Actualmente, cuando los pueblos y los gobiernos están sometiendo a un escrutinio más profundo el proceso de reformas, conviene volver a utilizar esos instrumentos analíticos y, en especial, considerar la aspiración a una adecuada absorción productiva de la fuerza de trabajo como objetivo orientador del desarrollo.

Este artículo pretende asimismo llamar la atención sobre el vínculo teórico existente entre la preocupación de los economistas por la absorción productiva de la fuerza de trabajo y la de los sociólogos por la movilidad social de tipo estructural. A menudo no se ha advertido que ése es un punto de convergencia de la mayor importancia entre ambas disciplinas y que podría dar lugar a esfuerzos interdisciplinarios encaminados a conocer mejor la evolución del desarrollo en las últimas décadas y ayudar a su necesaria reorientación.

El presente análisis comienza por esbozar el planteamiento hecho por Prebisch sobre la absorción productiva de la fuerza de trabajo en sus primeros estudios en la CEPAL, tratando de destacar el lugar privilegiado que le otorgó tanto en su evaluación crítica del patrón de desarrollo hacia afuera como en su propuesta de estrategia de desarrollo centrada en la industrialización. En seguida examina dos trabajos, uno de Prebisch y otro de Pinto, escritos veinte años después de los planteamientos iniciales, en los cuales se juzga lo sucedido con la absorción productiva entre 1950 y 1970 en América Latina. Sus conclusiones no son favorables, por lo que, cada uno a su manera, proponen acelerar el ritmo y modificar el rumbo del desarrollo económico. Este diagnóstico inquietante no es compartido por otros estudios realizados en la CEPAL a principios de la década de 1980 que, a partir del análisis del período 1950-1980, concluyen que habría existido una absorción productiva muy considerable impulsada por el fuerte ritmo de crecimiento económico de aquellos años. Según tales estudios, los trabajos de Prebisch y Pinto no habrían prestado la debida atención a las transformaciones positivas que los incrementos de la productividad del trabajo habían producido en la estructura de la fuerza de trabajo. Por su parte, algunos estudios del Programa de Empleo para 
América Latina y el Caribe (PREALC), de la Organización Internacional del Trabajo (огт), sostienen que ambos puntos de vista tienen su cuota de razón, pues en aquellos años se habría producido un proceso ambivalente en que coexistió un fuerte ritmo de absorción con la persistencia del subempleo.

En esta controversia influyó el hecho de que Prebisch y Pinto, con el fin de alentar la aplicación de políticas que remediaran esa situación, hicieran hincapié en lo que no se había logrado en términos de absorción productiva: lo que subrayaban era que el vaso todavía estaba a medio llenar. Por cierto, no ignoraban que había existido absorción productiva pero sostenían que ella no había sido "suficiente", es decir, no había guardado relación con las necesidades. Sus críticos pusieron el mismo énfasis en ver los avances que sí se habían logrado en la absorción productiva: el vaso estaba a medio llenar y era dable esperar que terminara de llenarse en un plazo no demasiado largo. A esta diferencia de perspectivas se sumó el hecho de que ni unos ni otros contaron con estadísticas amplias y confiables que les permitieran sustentar con antecedentes irrefutables su posición, por lo que la controversia sigue abierta. ${ }^{1}$

Sobre la base de los estudios descritos, llevados a cabo sobre todo por economistas, los sociólogos de la CEPAL realizaron dos investigaciones sobre estratificación ocupacional, una a principios y otra a finales de la década de 1980. En ambas concluyeron que entre 1950 y 1980 habría habido un alza considerable de la productividad de la fuerza de trabajo que habría producido cambios notables en la estructura de la estratifica- ción ocupacional, en especial la expansión de la fuerza de trabajo no agrícola a expensas de la agrícola y, dentro de esta última, el crecimiento de las ocupaciones no manuales a expensas de las manuales. Dichos cambios a su vez se expresaron en una masiva movilidad ocupacional de tipo estructural. Como se verá más adelante, esta conclusión presenta algunos flancos débiles, por lo que también sigue abierta la controversia acerca de la real amplitud de la movilidad estructural en América Latina entre 1950 y 1980.

De todos modos, desde principios del decenio de 1980 el panorama económico de la región cambió y los procesos de absorción productiva y movilidad estructural se estancaron o retrocedieron en la mayoría de los países. En un comienzo, los economistas de la CEPAL concentraron su atención en los equilibrios macroeconómicos y los problemas del ajuste estructural, y los sociólogos en la tarea de estimar el costo social de los mismos y sugerir políticas sociales que permitieran paliar sus consecuencias. Sin embargo, en la década de 1990 se advirtió un retorno a aquellos temas, que se ha expresado en especial en una publicación anual de la CEPAL, Panorama social de América Latina. En la última parte de este artículo se examinan algunas de las ideas presentadas en esa publicación sobre lo sucedido con la absorción productiva y la estratificación ocupacional entre principios de la década de 1980 y mediados de la de 1990, y se sintetizan los principales hallazgos del último estudio llevado a cabo en la CEPAL sobre estratificación ocupacional en América Latina (CEPAL, 2000, cap. 2).

II

\section{Absorción productiva de la fuerza de trabajo, 1950-1980}

\section{La idea de absorción productiva en los prime- ros planteamientos de Prebisch en la CEPAL}

El núcleo del pensamiento cepalino clásico, elaborado por Prebisch entre fines del decenio de $1940 \mathrm{y}$ principios del de $1950,{ }^{2}$ gira en torno a la idea de la expan-

\footnotetext{
${ }^{1}$ Véase Centro de Proyecciones Económicas (1984).

${ }^{2}$ Los principales escritos de Raúl Prebisch en aquel período fueron: El desarrollo económico de América Latina y algunos de sus principales problemas (Prebisch, 1949); Crecimiento, desequilibrio
}

sión y distribución del progreso técnico y sus "frutos", y sintetiza su creencia de que el mejoramiento de las condiciones materiales de vida depende sobre todo del desarrollo científico-tecnológico, en especial del

\footnotetext{
y disparidades: interpretación del proceso de desarrollo económico (Prebisch, 1950), que apareció como primera parte del Estudio Económico de América Latina 1949; y Problemas teóricos y prácticos del crecimiento económico (Prebisch, 1952). Los dos primeros en su totalidad y los tres primeros capítulos del tercero fueron reproducidos en Gurrieri (comp.), 1982.
} 
aplicado a las actividades económicas. De acuerdo con esa creencia, el principal objetivo económico de largo plazo de los países latinoamericanos debiera ser la elevación de la productividad de su fuerza de trabajo, para asemejarla a la de los centros. Lo medular de sus trabajos está dedicado a demostrar que el patrón de desarrollo hacia afuera, predominante hasta la crisis de la década de 1930, era incapaz de lograr ese objetivo, por lo que debía reemplazarse por otro que hiciera especial hincapié en la industrialización; el análisis de las razones de esa incapacidad constituyó la parte más importante del diagnóstico de la economía latinoamericana realizado por Prebisch en esos años. Aquel patrón de desarrollo habría surgido históricamente como consecuencia de la forma que asumió la generación y difusión del progreso técnico a nivel internacional a partir de finales del siglo XVIII. Los países en los cuales el progreso técnico se originó y alcanzó un gran impulso se constituyeron en los "grandes centros industriales" en torno a los cuales se formó una amplia y heterogénea "periferia" que se vinculó a los centros de manera parcial y subordinada a los intereses de estos últimos: se trata del "sistema centro-periferia" en el cual quedaron insertos los países latinoamericanos. El predominio de los intereses de los centros en el funcionamiento del sistema en su conjunto implica que éste no estuvo primordialmente orientado a elevar la productividad, el ingreso ni las condiciones de vida en los países periféricos, aunque tales objetivos se hayan logrado en muchos de ellos; durante ese período el progreso técnico penetró en la mayoría de los países periféricos de un modo " lento" e "irregular". Lento, en relación a las necesidades de crecimiento económico y absorción productiva de esos países, e irregular porque sólo se expandió de manera importante en las actividades económicas dedicadas a la exportación hacia los centros.

Esa penetración lenta e irregular del progreso técnico contribuyó a configurar estructuras productivas heterogéneas en los países de la periferia. En otras palabras, el patrón de desarrollo hacia afuera impulsó la penetración del progreso técnico y la consiguiente absorción productiva de fuerza de trabajo, pero este proceso fue en general más lento que lo deseable en función de las necesidades de los países latinoamericanos y se restringió a aquellos sectores y regiones que de manera directa o indirecta estuvieron vinculados a la producción para la exportación. En tales circunstancias, una proporción de la fuerza de trabajo, variable según los países pero importante en el conjunto de la región, no se favoreció con la penetración del progreso técnico estimulado por el crecimiento hacia afuera. A juicio de
Prebisch, este tipo de desarrollo produjo un doble proceso de concentración del progreso técnico y sus frutos: en los países centrales en relación con los periféricos y, dentro de éstos, en los sectores y zonas que se desarrollaban en relación con las que quedaban marginadas. En los escritos citados, Prebisch dedica mucha más atención a la distribución del progreso técnico y sus frutos en el sistema económico internacional que a la distribución dentro de las economías periféricas; esta última sería examinada con mayor detención por Aníbal Pinto (1973) algunos años después, usando el concepto de heterogeneidad estructural. Sin embargo, ambos compartían la idea de que la evolución de la absorción productiva de fuerza de trabajo dependía en especial del tipo de relación que las economías latinoamericanas establecieran con las de los países centrales.

Prebisch analizó las causas por las cuales en el período de desarrollo hacia afuera no se produjo una irradiación del progreso técnico y sus frutos hacia los países de América Latina en el grado y amplitud en que hubiera sido deseable; como en la inmediata posguerra los flujos financieros internacionales no eran significativos, concentró su análisis en la dimensión comercial de las relaciones centro-periferia. Respecto a ellas, puso de relieve la existencia en el largo plazo de un deterioro de los precios de los productos primarios en relación con los industriales, lo que habría permitido a los centros industriales no sólo retener los frutos de los incrementos de productividad generados por ellos mismos, sino además apropiarse de una parte de los generados por los países de la periferia. En otras palabras, los centros no difundieron hacia la periferia una parte de los frutos generados por su propio progreso técnico, como habría esperado la teoría convencional, sino que, al contrario, pudieron retenerlos y, además, apropiarse de una parte de los generados por la periferia.

Este fenómeno responde a una gran diversidad de causas, entre las que destacan la inelasticidad de la oferta de productos agropecuarios; la mayor capacidad relativa de los agentes económicos de los países centrales - empresarios y obreros - para defender y aumentar su nivel de ingresos; las políticas proteccionistas que los gobiernos de esos países aplican para proteger las actividades productivas que pueden verse amenazadas por las importaciones de la periferia, como es el caso de los productos agropecuarios; la posición subordinada que en términos de dinamismo económico tienen las actividades productoras de bienes primarios en relación a las de bienes industriales (el aumento de la actividad industrial estimula la actividad primaria pero el incremento 
de esta última no puede estimular a la primera, por lo que Prebisch afirma que existirían límites a las exportaciones de la periferia impuestos por el dinamismo económico de los centros que los países periféricos no pueden sobrepasar); los cambios provocados por el incremento del nivel de ingreso en los centros y en la periferia que modifican la composición de la demanda en favor de los productos industriales y en desmedro de los primarios, generando una disparidad de elasticidades-ingreso de la demanda de importaciones entre ambos tipos de países que deteriora los precios relativos de los productos primarios; $y$, finalmente, la reducida movilidad internacional de la fuerza de trabajo que, de ser mayor, habría permitido que la fuerza laboral de la periferia se incorporase al proceso de industrialización de los centros, aumentando así su nivel de productividad e ingresos $y$, de paso, dejando de deprimir los salarios y los precios de los productos de exportación en sus países.

Todos estos factores fueron perfilando el diagnóstico de la situación que formuló Prebisch a fines del decenio de 1940 respecto a la absorción productiva de fuerza de trabajo en la mayoría de los países de América Latina: existencia de una abundante oferta de fuerza de trabajo "inmovilizada" que no puede trasladarse a los centros industriales y tampoco puede elevar en sus países su nivel de productividad, por la existencia de un patrón de desarrollo en que el progreso técnico aumenta de manera más lenta y menos generalizada de lo que sería necesario para poder absorberla productivamente. A ello se agrega que el mismo progreso técnico impulsa en los países periféricos el crecimiento de la población, al reducir la tasa de mortalidad, y favorece (en los sectores dedicados a la exportación hacia los centros y limitadamente en el resto) la utilización de técnicas productivas que economizan mano de obra.

En tales circunstancias, Prebisch argumentó en contra de las voces que en la inmediata posguerra se elevaron en favor del restablecimiento, ampliación y profundización de las bases de funcionamiento de la modalidad de desarrollo hacia afuera desbaratadas por la guerra pues, a su juicio, sería equivocado concentrar el dinamismo económico en actividades que, además de ser muy vulnerables a factores externos, no podrían responder a las exigencias de absorber productivamente la fuerza de trabajo que enfrentaban los países de la región. Sin embargo, reiteró que sus conclusiones se referían al conjunto de América Latina y debían aplicarse con cautela a las diferentes situaciones nacionales y a productos de exportación específicos. La aceptación o rechazo de este patrón de desarro- llo debiera basarse en una evaluación pragmática sobre su capacidad de sostener un ritmo acelerado y estable de desarrollo en las diferentes situaciones nacionales concretas. Sostuvo además que su crítica al patrón de desarrollo basado en el dinamismo de las exportaciones a los centros no implicaba ningún sesgo antiexportador, ya que las actividades exportadoras debían seguir desempeñando un papel decisivo en el desarrollo de los países periféricos, entre otras razones, porque había que seguir aprovechando las oportunidades que ellas brindaban y porque la industrialización requería un volumen significativo de importaciones.

A partir de esta crítica, Prebisch propuso una modalidad de desarrollo centrada en la industrialización que aumentaría la productividad del trabajo, el nivel general de ingreso y el potencial de acumulación de capital, los cuales se irían irradiando al resto de los sectores, reduciendo así el nivel de heterogeneidad y especialización de la estructura productiva. Una de las consecuencias sociológicas más relevantes de este proceso sería el incremento de la movilidad estructural, que se produciría debido al impacto de los cambios técnicos y económicos en el tamaño absoluto y relativo de los estratos ocupacionales y en el contenido de las ocupaciones, y que mejoraría la proporción de ocupaciones no manuales, industriales y de otras ramas urbanas con mayor productividad. Por supuesto, no es posible examinar aquí ni siquiera el contenido general de su propuesta, sino sólo subrayar que la industria debía tener un papel muy destacado en la superación de las falencias que Prebisch había advertido en el patrón primario exportador, sobre todo en cuanto a la elevación de la productividad del trabajo y el mejoramiento de las condiciones de vida que requerían los países latinoamericanos.

\section{Evaluaciones de la absorción productiva en el período 1950-1970 efectuadas por la CEPAL}

Como es sabido, la industrialización ganó impulso en la mayoría de los países de la región entre 1950 y 1970; en algunos era la continuación de un proceso que había comenzado en las décadas anteriores, en especial desde la crisis del decenio de 1930, y en otros una experiencia nueva. La intensidad de la industrialización varió bastante de un país a otro. En la CEPAL el proceso se siguió con gran atención y desde fines de la década de 1950 comenzaron a aparecer estudios en los cuales se analizaba de manera crítica sus logros y fracasos. Al principio, preocuparon en especial las consecuencias 
adversas para el balance de pagos derivadas de un tipo de industrialización que no utilizaba su potencial exportador; pero a partir de fines de la década de 1960 también se examinaron sus efectos en la absorción productiva de la fuerza de trabajo. Entre esos estudios destacan dos, uno de Raúl Prebisch y otro de Aníbal Pinto, ambos publicados en 1970, que sintetizan la evaluación del proceso de absorción productiva que en aquella época se hacía en la CEPAL.

\section{a) Prebisch en "Transformación y desarrollo"3}

El Banco Interamericano de Desarrollo le solicitó a Prebisch que preparase un informe sobre el papel que la cooperación financiera internacional estaba cumpliendo y debía cumplir en el desarrollo de América Latina. Para realizar esa tarea Prebisch partió estableciendo las metas deseables de desarrollo económico que la región debía alcanzar, las que debían dar consideración especial a la absorción productiva de fuerza de trabajo. A su juicio, resultaba insuficiente establecer metas referidas solamente al crecimiento del producto sin considerar el impacto que el mismo tendría sobre dicha absorción, ya que éste era el objetivo principal del desarrollo económico.

"Cabe preguntarse qué significación tiene el establecer como meta tal o cual tasa de desarrollo si no se la relaciona con la absorción productiva de fuerza de trabajo. Estuvo bien que hace diez años se tomara del aire liviano una cifra de 5\% como expresión de aspiraciones. Ahora hay que ir más a fondo y persuadir a los países a profundizar más en estas materias" (Prebisch, 1970, pp. 98 y 99).

$\mathrm{Al}$ evaluar lo sucedido entre 1950 y 1970 los resultados le parecen muy inquietantes. Reconoce que ha habido avances importantes, como el crecimiento y modernización de las ciudades, el desarrollo y diversificación de la industria, y la elevación del nivel de vida de los estratos medios; pero a su juicio persiste el problema de que los "frutos" de ese desarrollo no han llegado a las "masas rezagadas", que estima en un $60 \%$ para el conjunto de América Latina. La absorción productiva de ellas tendría consecuencias económicas, sociales y políticas de la mayor importancia: eliminaría el enorme desperdicio de potencial humano que implica su falta de inserción; permitiría ampliar de manera considerable el mercado interno, impulsando así la expansión

\footnotetext{
${ }^{3}$ Transformación y Desarrollo. La gran tarea de América Latina (Prebisch, 1970).
}

del aparato productivo; contribuiría a reducir la inequidad social, y mejoraría la integración social y la estabilidad política.

Al examinar las causas que explicarían los resultados de las economías latinoamericanas en cuanto a absorción productiva, Prebisch destaca ante todo el notable aumento de la fuerza de trabajo - estima su crecimiento medio anual entre 1950 y 1965 en 2,6\%impulsado por el crecimiento demográfico, aunque subraya las importantes diferencias que al respecto existen entre los países de la región. Las actividades agrícolas no podrían haber absorbido ese incremento, cualesquiera hubiesen sido las políticas económicas aplicadas, pero su desempeño podría haber sido mejor si, por ejemplo, hubiese aumentado la demanda interna y externa de productos agrícolas, si las tecnologías aplicadas no hubiesen hecho tanto hincapié en la economía de mano de obra y si se hubiese dado mayor importancia a programas para retener mano de obra en el agro, como los de extensión de la frontera agrícola y la reforma agraria. Impulsada por la migración del campo a las ciudades, la fuerza de trabajo no agrícola creció a una tasa media anual de 3,5\% entre 1950 y 1965 y la agrícola a una de $1,5 \%$ (cuadro 1 ).

Respecto a la fuerza de trabajo no agrícola, afirma que lo ideal hubiera sido que ella hubiese crecido con mayor intensidad en las ocupaciones pertenecientes a lo que denomina el "grupo de la industria" — que abarca la industria, la construcción y la minería-, pero que esto no sucedió. Por el contrario, la proporción de la fuerza de trabajo en el grupo de la industria habría descendido de $35 \%$ a $30 \%$ en el medio urbano entre 1950 y 1970 . La fuerza de trabajo que no fue absorbida en el grupo industrial se habría incorporado a los servicios, que habrían aumentado de $65 \%$ a $70 \%$ entre esos años. En cuanto a la evolución de los distintos tipos de servicios, advierte que ha crecido el empleo en los calificados - transporte, energía y demás servicios básicos, comercio y finanzas, administración pública y servicios personales calificados- pero en una proporción mayor a lo deseable; este tipo de empleo debiera acrecentarse con el desarrollo económico, pero en América Latina habría aumentado en demasía debido a una absorción "redundante" de fuerza de trabajo, en especial en la administración estatal y los servicios públicos. ${ }^{4}$ También habría aumentado el empleo en los servicios personales no calificados y en el comercio callejero, actividades que debieran haber expulsado

\footnotetext{
${ }^{4}$ Considera redundante a la fuerza de trabajo de la cual podría prescindirse sin por ello disminuir la producción de bienes y servicios.
} 
A. Crecimiento de la fuerza de trabajo

(Tasas acumulativas anuales expresadas en porcentajes para el período 1950-1965)

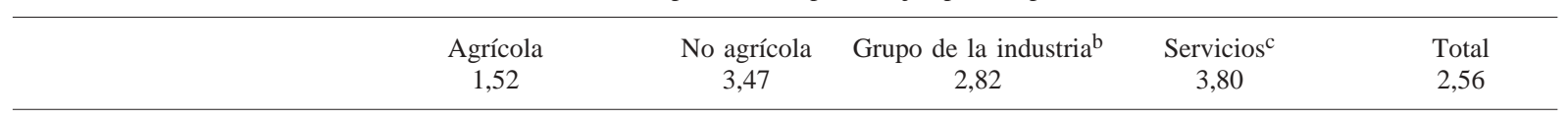

B. Distribución de la fuerza de trabajo

\begin{tabular}{lccc}
\hline Año & $\begin{array}{c}\text { (Porcentajes de la fuerza de trabajo total) } \\
\text { Agrícola }\end{array}$ & No agrícola & $\begin{array}{c}\text { (Porcentajes de la fuerza de trabajo no agrícola) } \\
\text { Grupo de la industria }{ }^{b}\end{array}$ \\
1950 & 50,2 & 49,8 & 35,0 \\
1965 & 43,1 & 56,9 & 65,0 \\
\hline
\end{tabular}

Fuente: Prebisch, 1970, p. 34.

a Excluye Cuba por falta de información.

b Incluye industria, construcción y minería.

c Incluye la desocupación abierta.

mano de obra, al tiempo que persistiría la redundancia en la agricultura y aun en el grupo de la industria.

Al evaluar de manera global los cambios acaecidos en la fuerza de trabajo entre 1950 y 1970 concluye que, pese al crecimiento económico alcanzado en ese período, se ha producido una "deformación de la estructura de la fuerza de trabajo" debido sobre todo a que el grupo de la industria no cumplió su papel absorbente, permitiendo así que los servicios crecieran en forma desproporcionada.

De acuerdo con ese diagnóstico, el objetivo principal debiera ser el de corregir dicha deformación mediante la transferencia de fuerza de trabajo desde la agricultura y los servicios al grupo de la industria; tal objetivo debiera ir acompañado en lo posible por un aumento del producto por persona ocupada en los tres sectores. En términos concretos, propone como meta recuperar entre 1970 y 1980 la proporción de 35\% —en relación al total de la fuerza de trabajo no agrícola- que el empleo en el grupo industrial había tenido en 1950. La transferencia de fuerza de trabajo de los sectores de menor a los de mayor productividad, en un contexto de mucho aumento de la fuerza de trabajo, exige un ritmo de crecimiento acelerado. Según sus cálculos, para alcanzar dicha meta se requeriría crecer a una tasa media anual de 7\%, siempre que no aumentase el producto por persona ocupada. Sin embargo, sería deseable que esto último también sucediera, pues significaría que dentro de cada sector se estaría transfiriendo fuerza de trabajo de actividades de menor a las de mayor productividad: del artesanado a la industria fabril, de los servicios menos calificados a los más calificados, y de la agricultura más atrasada a la más moderna. Pero entonces sería necesario aumentar más allá del 7\% la tasa media anual de crecimiento económico durante la década para alcanzar la "suficiencia dinámica" requerida por las metas de absorción productiva.

Con la perspectiva que brinda el tiempo transcurrido, resaltan en ese informe dos flancos débiles, uno metodológico y otro teórico. El primero se refiere a los criterios operacionales que utilizó Prebisch para estimar estadísticamente las diferencias de productividad en la fuerza de trabajo. ${ }^{5} \mathrm{El}$ segundo está referido a la conclusión que él presenta de la evolución de la estructura de la fuerza de trabajo en América Latina en las dos décadas bajo estudio, pues no asigna mayor relieve a los logros alcanzados en aquellos años en cuanto a absorción productiva. Por supuesto, a la luz del retroceso que tuvo lugar entre 19802000, la absorción de 1950-1970 resulta excepcional. Sin embargo, en descargo de Prebisch es conveniente

\footnotetext{
${ }^{5}$ En su análisis advierte que existe fuerza de trabajo con diferentes niveles de productividad en todos los sectores, con la excepción de los servicios personales de baja calificación y la venta callejera, que considera no productivos en su totalidad. Los datos disponibles no le permitieron desagregar el conjunto de la fuerza de trabajo de acuerdo con ese criterio, por lo que utilizó una aproximación estadística según la cual la fuerza de trabajo no agrícola se divide en dos conjuntos: i) la ocupada en el grupo industrial, que tendría mayor productividad, y ii) la ocupada en los servicios, que tendría menor productividad. A esta última agrega la que está desocupada, obteniendo así las cifras a partir de las cuales afirma que entre 1950 y 1970 se habría agravado la "deformación" de la estructura de la fuerza de trabajo, cuya corrección debiera constituir un objetivo principal de la estrategia de desarrollo.
} 
recordar que no ignoraba las importantes transformaciones económicas y sociales del período que estudió, pero estaba especialmente interesado en destacar lo que no se había logrado en cuanto a absorción productiva con la finalidad de establecer las metas de la política de desarrollo, es decir, lo que se debía hacer. Persistía el hecho de que un $60 \%$ de la población latinoamericana estaba al margen de los beneficios del desarrollo, lo que debía ser decisivo para orientar la política de desarrollo. Quiso evitar que el beneplácito con lo alcanzado hiciera olvidar la magnitud del desafío pendiente.

\section{b) Pinto en "Heterogeneidad estructural"}

Pinto $^{6}$ también evalúa de manera crítica la capacidad de absorción que mostraron las economías de América Latina entre 1950 y 1970, lo que se pondría de manifiesto de manera destacada en el alto grado de heterogeneidad estructural que todavía caracteriza a la mayoría de ellas al final de ese período. En otras palabras, en dichas economías coexisten actividades económicas, estratos socioeconómicos y regiones que exhiben diferencias muy marcadas de productividad e ingreso. Dicho concepto está estrechamente vinculado al de absorción productiva de fuerza de trabajo en tanto el grado de heterogeneidad estructural existente en un país dado refleja el avance logrado en materia de absorción. Los países de América Latina presentan diferencias importantes en sus grados de heterogeneidad, los que sin embargo, como expresión de un menor nivel de desarrollo, siempre son mayores que los existentes en los países centrales.

En diversos trabajos Pinto intenta presentar una caracterización histórica de la evolución de la heterogeneidad estructural y los diferentes tipos estructurales predominantes. Durante el período en que predominó el patrón de desarrollo primario exportador, todas las estructuras productivas de la región tenían dos sistemas bien desiguales en cuanto a productividad e ingresos - el complejo agroexportador y el resto de la economía. El rasgo que diferenciaba a los países era la mayor o menor irradiación de ese complejo hacia el resto de la economía. En las economías de tipo enclave esa irradiación fue muy escasa y alto el grado de heterogeneidad, pero en otras, como en las del Cono Sur, la irradiación fue mucho mayor y la heterogeneidad me-

\footnotetext{
6 "Heterogeneidad estructural y modelos de desarrollo reciente de
} la América Latina" (Pinto, 1973). nor. En tales diferencias influyeron, entre otros factores, el tipo de productos que se exportaban, la mayor o menor consolidación del Estado nacional y las características de la economía tradicional. Cuanto mayor era la separación entre los dos sistemas mayor era el desnivel de productividad e ingresos entre ellos, que en general fue bastante pronunciado.

Con el desarrollo de la industrialización, sobre todo en la etapa más avanzada de ella que se dio después de 1950 en los países latinoamericanos de industrialización más temprana, cambió el tipo de heterogeneidad estructural debido a la aparición de un sector moderno no exportador, que alcanzó niveles de productividad similares a los del sector exportador. En tales circunstancias, la dualidad inicial es sustituida por una estructura de tres estratos con diferentes niveles de productividad e ingresos: el primitivo, el intermedio y el moderno. Pinto argumenta que todos los estratos son multisectoriales, es decir, abarcan segmentos de todos los sectores productivos, pero algunos sectores tienden a poseer un mayor nivel relativo de productividad e ingreso, como la industria fabril.

Con el objeto de precisar sus ideas sobre la heterogeneidad estructural existente en América Latina, compara la estructura y tendencias latinoamericanas con las de los centros. Ante todo, subraya que las estructuras de estos últimos serían mucho más homogéneas que las de América Latina; por ejemplo, en la región el estrato moderno tendría cuatro veces la productividad del promedio de la economía mientras que el estrato primitivo tendría sólo la cuarta parte, dando lugar a un nivel de desigualdad entre ellos mucho mayor que el existente en los centros. Además, entre los países centrales y los de América Latina existirían diferencias apreciables en la magnitud de los estratos; el estrato primitivo sería mucho mayor en América Latina, ya que ocuparía entre el $35 \%$ y el $40 \%$ de la fuerza de trabajo, mientras que el moderno sería mucho más pequeño, ocupando sólo el 13\% de ella. Finalmente, concluye que la heterogeneidad estructural en América Latina entre 1950 y 1970 se ha acentuado, también a diferencia de lo acaecido en los países centrales. En estos últimos se aplicaron políticas económicas y sociales que fortalecieron la capacidad de arrastre de los focos dinámicos del sector moderno y estimularon la difusión de los beneficios del desarrollo, dando lugar a la formación de estructuras económicas, sociales y espaciales más homogéneas. Al contrario, en América Latina habría predominado una modalidad de desarrollo que generó un ritmo de crecimiento económico débil, provocó un aumento de la dependencia externa comer- 


\begin{tabular}{|c|c|c|c|c|c|c|}
\hline & \multicolumn{3}{|c|}{$1950-1960$} & \multicolumn{3}{|c|}{$1960-1969$} \\
\hline & Incremento & $\begin{array}{c}\text { Distribución } \\
\text { porcentual }\end{array}$ & $\begin{array}{l}\text { Tasas anuales } \\
\text { de crecimiento }\end{array}$ & Incremento & $\begin{array}{c}\text { Distribución } \\
\text { porcentual }\end{array}$ & $\begin{array}{c}\text { Tasas anuales } \\
\text { de crecimiento }\end{array}$ \\
\hline Total & 14810 & 100,0 & 2,6 & 18276 & 100,0 & 2,8 \\
\hline Total, excluidas actividades no especificadas & 13642 & & 2,5 & 15891 & & 2,3 \\
\hline Agricultura & 3865 & 26,1 & 1,3 & 4465 & 24,4 & 1,5 \\
\hline Bienes y servicios básicos no agrícolas & 4212 & 28,4 & 3,1 & 4590 & 25,1 & 2,8 \\
\hline - Industrias manufactureras & 2150 & 14,5 & 2,6 & 2124 & 11,6 & 2,3 \\
\hline - Fabril & 1530 & 10,3 & 3,7 & 1463 & 8,0 & 2,9 \\
\hline - Artesanal & 620 & 4,2 & 1,5 & 661 & 3,6 & 1,6 \\
\hline - Construcción & 721 & 4,9 & 3,2 & 1118 & 6,1 & 4,0 \\
\hline - Servicios básicos & 1222 & 8,2 & 4,6 & 1201 & 6,6 & 3,4 \\
\hline Servicios & 6733 & 45,5 & 4,7 & 9221 & 50,5 & 4,6 \\
\hline - Comercio y finanzas & 1947 & 13,2 & 4,1 & 2559 & 14,0 & 4,1 \\
\hline Actividades no especificadas & 1167 & 7,9 & 7,3 & 2385 & 13,1 & 8,2 \\
\hline
\end{tabular}

Fuente: Pinto, 1973, p. 115.

cial y financiera, aumentó la concentración del ingreso y de la población en el espacio y, sobre todo, no impulsó un proceso importante de absorción de la fuerza de trabajo en el sector moderno. Aún más, Pinto sostiene que lo más probable es que en el futuro se mantengan esas tendencias, lo que daría por resultado una acentuación todavía mayor de la heterogeneidad estructural.

Para dar fundamento empírico a sus afirmaciones acerca de la escasa absorción productiva del sector moderno entre 1950 y 1970, Pinto examina cómo se absorbió el incremento de fuerza de trabajo que se produjo entre 1950-1960 y 1960-1969. Al igual que Prebisch, concuerda con que los desniveles de productividad conforman estratos multisectoriales, pero los datos estadísticos disponibles lo obligaron a dividir entre sectores: la industria fabril y los servicios básicos serían las actividades más modernas mientras que la agricultura, el artesanado y los servicios no especificados constituirían las más tradicionales o primitivas. ${ }^{7}$ Destaca que si bien la fuerza de trabajo en la agricultura creció a un ritmo medio anual bajo $(1,3 \%$ en el primer decenio y $1,5 \%$ en el segundo), continuó absorbiendo alrededor del $25 \%$ del incremento de la fuerza

\footnotetext{
${ }^{7}$ De todos modos, se apoyó en las mejores estadísticas disponibles en la época para evaluar la heterogeneidad estructural y, en especial, reconoció la ayuda que le brindaron los informes que Zygmunt Slawinski preparó para la CEPAL (véase Slawinski, 1964).
}

de trabajo; la ocupada en la industria fabril creció a tasas superiores al promedio pero declinantes $(3,7 \%$ y $2,9 \%$, respectivamente), reduciendo la proporción de fuerza de trabajo absorbida de $10,3 \%$ a $8,0 \%$; los servicios básicos también tuvieron un desempeño insatisfactorio, semejante al de la industria fabril, disminuyendo su tasa de crecimiento y la proporción de fuerza de trabajo que incorporan; y, por el contrario, los servicios no especificados aumentaron a ritmo rápido $(7,9 \%$ en el primer decenio y $8,2 \%$ el segundo) de modo que la proporción de fuerza de trabajo absorbida por ellos pasó de $7,9 \%$ a $13,1 \%$ (cuadro 2 ).

En suma, el diagnóstico de Pinto sobre lo sucedido en términos de superación de la heterogeneidad estructural es bastante negativo, lo mismo que su pronóstico, basado en las tendencias concentradoras que observa en el estilo de desarrollo predominante. Dicho diagnóstico tiene algunas diferencias con el de Prebisch, pero ambos comparten una idea principal: no están satisfechos con el dinamismo y la orientación de la industrialización entre 1950 y 1970, cuyos resultados no fueron buenos en lo que se refiere a la absorción productiva de la fuerza de trabajo y la homogeneización de la estructura productiva.

A los trabajos de Pinto se le pueden encontrar las mismas falencias que al de Prebisch en cuanto a la información que presentan y al juicio severo acerca de la evolución de la heterogeneidad estructural. Los descargos son también los mismos. Respecto a lo primero, utilizó los mejores datos disponibles en aquellos 
años y, en relación a lo segundo, la severidad de su evaluación deriva de los ideales que tenía, de lo que esperaba que llegaran a ser las sociedades latinoamericanas.

\begin{abstract}
“Existe alguna posibilidad razonable de que estos países, en su actual nivel de desarrollo, al mismo tiempo reproduzcan las formas de consumo de las naciones centrales [para una obligada minoría], satisfagan las necesidades básicas de la gran mayoría y, por último, establezcan las bases para un desarrollo autosustentado y (relativamente) autónomo?” (Pinto, 1973, p. 136).
\end{abstract}

\section{La visión más optimista de principios del de- cenio de 1980}

Hacia principios de la década de 1980, favorecidos por la disponibilidad de mejores datos estadísticos, aparecieron varios estudios que permitieron examinar con más profundidad lo sucedido desde 1950 en adelante en materia de absorción productiva de la fuerza de trabajo y sus efectos sobre la estructura ocupacional. Prebisch y Pinto habían hecho hincapié en los objetivos que no se habían logrado y que, por lo tanto, debían seguir presentes como guías de la política económica y social; no ignoraban las transformaciones que se habían producido pero no estaban satisfechos con su orientación ni con el grado en que habían resuelto el problema decisivo de la integración productiva y social de los estratos más rezagados.

\section{a) Estudios de la CEPAL}

Los estudios realizados a comienzos de la década de 1980 se concentraron más en el examen de la otra cara de la moneda, es decir, en las transformaciones positivas que se produjeron en la estructura de la fuerza de trabajo desde 1950 en adelante. Cabe apuntar al respecto que esos estudios contribuyeron a revalorizar el proceso de desarrollo de aquellas décadas, postura que se justificó aún más cuando en años posteriores - sobre todo en la denominada década perdida- se añoraba el crecimiento económico y la mejora en las condiciones de vida logrados entonces. Entre los estudios realizados en la CEPAL que pusieron énfasis en los éxitos en materia de absorción productiva alcanzados en América Latina puede mencionarse el de Kaztman (1984). En contraposición a las tesis de Prebisch y Pinto, este autor subraya que tanto la industria como los servicios habrían cumplido un papel destacado en la absorción de fuerza de trabajo. Afirma que en varios países de la región la población económicamente activa (PEA) industrial creció más que la no agrícola y que no es cierto que la industria moderna haya absorbido con lentitud su propia PEA informal, pues en cinco de los nueve países de la región examinados habría aumentado más la PEA industrial moderna que la industrial en su conjunto durante 1950-1970, lo que también habría sucedido en tres de seis países en el decenio posterior. En cuanto al sector terciario, sostiene que no debe ser considerado como un conjunto de actividades poco productivas que han dado refugio a la fuerza de trabajo que no ha podido emplearse en la industria. Por ejemplo, en los servicios habría crecido más la fuerza de trabajo que está ocupada en los que considera de mayor productividad - como los productivos (bancos, seguros, bienes raíces, etc.) y sociales (gobierno, salud, educación, etc.) - que en los que serían de baja productividad: los distributivos (transporte y comercio) y los personales. En el comercio, llama la atención que en varios países latinoamericanos existe una proporción de fuerza de trabajo por cuenta propia o familiares no remunerados que no deberían ser considerados informales sino más bien parte de empresas familiares que tienen un mayor nivel de productividad que el que se les atribuye (cuadro 3). En suma, concluye que la industrialización ha desempeñado un papel de importancia en la absorción productiva de fuerza de trabajo, que los servicios se han estado integrando de manera progresiva a dicho proceso, lo que ha impulsado su productividad, y que no ha habido avance de la informalidad en ninguno de esos sectores.

Sin embargo, la información que presenta Katzman no es concluyente ya que entre 1950 y 1970 son muchos los países que no han seguido la evolución señalada y entre 1970 y 1980 los datos de que dispone son tan escasos que no permiten formarse una idea clara de lo que sucedió. ${ }^{8}$ Más allá de las críticas que puedan formularse a este estudio y a otros semejantes respecto a sus apoyos estadísticos y definiciones operacionales — defectos que, como se señaló, también

\footnotetext{
${ }^{8}$ Además, es probable que la definición que utiliza para distinguir la PEA industrial moderna de la informal puede haberlo inducido a sobrestimar el volumen de la primera, ya que pertenecerían a ella todos los trabajadores del sector excepto los que trabajan por su cuenta o son familiares no remunerados. En otras palabras, al suponer que la PEA industrial informal está constituida sólo por las mencionadas categorías ocupacionales puede estar subestimando el número de trabajadores de baja productividad existentes en ese sector como, por ejemplo, una buena parte de los que trabajan en empresas pequeñas.
} 


\begin{tabular}{|c|c|c|c|c|c|c|c|c|c|c|}
\hline \multirow[t]{2}{*}{ Países $^{\mathrm{a}}$} & \multicolumn{4}{|c|}{ Porcentaje de la PEA en la industria } & \multicolumn{4}{|c|}{$\begin{array}{l}\text { Crecimiento de la PEA en la industria/ } \\
\text { crecimiento de la PEA no agrícola }\end{array}$} & \multicolumn{2}{|c|}{$\begin{array}{c}\text { Crecimiento de la } \\
\text { PEA en la industria } \\
\text { moderna/crecimiento } \\
\text { de la PEA no agrícola }\end{array}$} \\
\hline & 1950 & 1960 & 1970 & 1980 & $1950-1960$ & $1960-1970$ & $1950-1970$ & $1970-1980$ & $1950-1970$ & $1970-1980$ \\
\hline Haití & 4,9 & $6,3^{b}$ & 7,8 & $\cdots$ & $\ldots$ & $\ldots$ & 0,83 & $\cdots$ & $\cdots$ & $\cdots$ \\
\hline Honduras & 11,5 & 7,9 & 10,5 & $\ldots$ & $-0,05$ & 1,45 & 0,62 & $\ldots$ & $\ldots$ & $\ldots$ \\
\hline Guatemala & 10,9 & 10,5 & 12,9 & $\ldots$ & 0,64 & 1,11 & 0,93 & $\ldots$ & $\ldots$ & $\ldots$ \\
\hline El Salvador & 11,9 & 12,9 & 11,3 & $\ldots$ & 0,91 & 0,43 & 0,62 & $\ldots$ & 0,74 & $\ldots$ \\
\hline Rep. Dominicana & 8,5 & 8,6 & 13,4 & $\ldots$ & 0,55 & 1,21 & 1,04 & $\ldots$ & $\ldots$ & $\ldots$ \\
\hline Bolivia & 8,2 & $9,8^{\mathrm{b}}$ & 11,3 & $\ldots$ & $\ldots$ & $\ldots$ & 0,58 & $\ldots$ & 0,68 & $\ldots$ \\
\hline Paraguay & 15,5 & 15,3 & 16,0 & $\ldots$ & 0,96 & 0,87 & 0,91 & $\ldots$ & $\ldots$ & $\ldots$ \\
\hline Ecuador & 10,1 & 13,9 & 15,6 & $\ldots$ & 1,54 & 0,91 & 1,18 & $\ldots$ & $\ldots$ & $\ldots$ \\
\hline Nicaragua & 11,4 & 11,5 & 14,6 & $\ldots$ & 1,00 & 0,88 & 0,93 & $\ldots$ & $\ldots$ & $\ldots$ \\
\hline Perú & $14,9^{\mathrm{b}}$ & 13,7 & 11,6 & $11,4^{\mathrm{cd}}$ & $\ldots$ & 0,01 & $\ldots$ & $0,38^{\mathrm{cd}}$ & $\ldots$ & $0,66^{\mathrm{c}}$ \\
\hline Brasil & 12,9 & 13,7 & 14,8 & 17,7 & 0,74 & 0,87 & 0,80 & 1,27 & 0,90 & 1,27 \\
\hline México & 12,2 & 13,7 & 18,5 & $\ldots$ & 0,93 & 1,22 & 1,08 & $\ldots$ & 1,21 & $\ldots$ \\
\hline Costa Rica & 11,2 & 11,5 & 13,7 & 16,1 & 0,72 & 0,99 & 0,89 & 0,89 & 1,00 & 0,94 \\
\hline Panamá & 8,7 & 8,6 & 9,9 & $10,5^{\mathrm{cd}}$ & 0,61 & 0,93 & 0,80 & $1,18^{\mathrm{cd}}$ & 0,96 & $1,69^{\mathrm{c}}$ \\
\hline Colombia & 12,5 & 13,0 & 17,3 & $\ldots$ & 0,75 & 1,08 & 0,95 & $\ldots$ & $\ldots$ & $\ldots$ \\
\hline Venezuela & 11,2 & 13,0 & 15,6 & $16,3^{\mathrm{c}}$ & 0,99 & 1,17 & 1,08 & $1,13^{c}$ & 1,22 & $1,28^{\mathrm{c}}$ \\
\hline Chile & 19,4 & 19,1 & 21,8 & $16,8^{\mathrm{c}}$ & 0,58 & 1,19 & 0,98 & $0,66^{\mathrm{c}}$ & 1,26 & $0,83^{\mathrm{c}}$ \\
\hline Uruguay & $21,7^{\mathrm{b}}$ & 23,4 & 23,0 & $\ldots$ & $\ldots$ & 0,76 & $\ldots$ & $\ldots$ & $\ldots$ & $\ldots$ \\
\hline Argentina & 25,3 & 27,7 & 24,0 & $\ldots$ & 1,12 & $-0,04$ & 0,55 & $\ldots$ & 5,15 & $\ldots$ \\
\hline
\end{tabular}

Fuente: Katzman, 1984, p. 90.

a Ordenados de mayor a menor según su porcentaje de PEA agrícola en 1970.

b No se levantaron censos. Estimaciones por interpoblación entre 1940 y 1960.

c Clasificación Industrial Internacional Uniforme de todas las actividades económicas (CIIU, Rev. 2): excluye talleres de reparaciones.

d Corresponde a población ocupada.

padecieron los estudios anteriores realizados en la CEPAL sobre el tema- ellos tuvieron la virtud de destacar los avances en absorción productiva realizados en aquellos años.

\section{b) Estudios del PREALC}

El escenario quedaba así dispuesto para que se intentara una visión de conjunto que rescatara las dos perspectivas, tanto la que llamaba la atención sobre lo que no se había logrado como la que subrayaba lo realizado. Esa visión la elaboró el Programa de Empleo para América Latina y el Caribe de la oIT en varios estudios realizados a principios de los años 80 , en los cuales presentó una interpretación más completa de lo sucedido entre 1950 y $1980 .{ }^{9}$

\footnotetext{
9 En la primera mitad de la década de 1980 aparecieron varias publicaciones institucionales o personales de funcionarios del PREALC donde se expusieron sus puntos de vista. Entre las principales pueden mencionarse: Dinámica del subempleo en América Latina (Tokman
}

La conclusión principal del PREALC es que el proceso de absorción entre 1950 y 1980 presenta dos tendencias, aparentemente contradictorias: por un lado, una escasa reducción del subempleo, que justifica las preocupaciones que Prebisch y Pinto habían formulado; por otro, un rápido ritmo de absorción productiva en el sector moderno de la economía, que da asidero a los que subrayan las importantes transformaciones que habían tenido lugar. Estas afirmaciones se fundamentan en un examen censal de la fuerza de trabajo dividida en cuatro grandes conjuntos [PEA agrícola tradicional, PEA agrícola moderna, PEA no agrícola formal

\footnotetext{
y García, 1981): Transformación ocupacional y crisis (Tokman y García, 1984); y Absorción creciente con subempleo persistente (García, 1982). Estos estudios, lo mismo que los mencionados antes, subrayan la existencia de importantes disparidades entre los países latinoamericanos en el proceso de absorción y las examinan en bastante detalle. Sin embargo, en este análisis general sólo se tomarán en cuenta las proposiciones que en ellos se hace en relación al conjunto de la región.
} 
y PEA no agrícola informal]; al examinar la evolución de las mismas desde distintos ángulos logran percibir sus tendencias variadas y aparentemente contradictorias. Con definiciones operacionales, ${ }^{10}$ los estudios del PREALC procuraron respetar el criterio de que los desniveles de productividad en la fuerza de trabajo se encuentran en todos los sectores y ocupaciones, realizando un corte transversal de éstos mediante las categorías ocupacionales de trabajadores por cuenta propia y familiares no remunerados. O sea, atribuyen a la fuerza de trabajo dos niveles de productividad —más productivos y menos productivos - mediante el uso de categorías ocupacionales; los empleadores y asalariados serían más productivos y los por cuenta propia —excepto los profesionales y técnicos- y los familiares no remunerados serían menos productivos. A partir de estos criterios examinan la evolución de la fuerza de trabajo en América Latina entre 1950 y 1980 y sus principales conclusiones generales son las siguientes:

a) Ante todo, destacan el masivo proceso de transferencia desde la fuerza de trabajo agrícola hacia la no agrícola: la primera se redujo de $54,7 \%$ en 1950 a $32,1 \%$ en 1980 , y la segunda aumentó de $44,1 \%$ a $67,1 \%$ (cuadro 4).

b) En cuanto a la fuerza de trabajo agrícola, señalan que su reducción no provocó, como hubiera sido deseable, una disminución mayor de la porción ocupada por el segmento tradicional, ya que se mantuvieron estables las proporciones de éste y del segmento moderno; la porción tradicional de la fuerza de trabajo agrícola, que abarcaba el 59,5\% de ella en 1950, sólo se había reducido a 58,8\% en 1980 . En otras palabras, la considerable merma de la fuerza de trabajo agrícola no tuvo como consecuencia una baja de la proporción de fuerza de trabajo tradicional que ya existía en 1950 (cuadro 5).

c) Por su parte, la fuerza de trabajo no agrícola creció de manera acelerada a una tasa de $4,0 \%$ anual durante el período examinado, pero desde el punto de vista de la evolución de sus segmentos formal e infor-

\footnotetext{
10 La PEA agrícola tradicional abarca a todos los trabajadores por cuenta propia y familiares no remunerados [estos últimos fueron aumentados para compensar la subestimación censal] y la PEA agrícola moderna incluye el número de trabajadores que surge de la diferencia entre la PEA agrícola total ajustada y la tradicional. La PEA no agrícola informal está conformada por los trabajadores por cuenta propia y familiares no remunerados de todas las ocupaciones excepto los profesionales y técnicos [a veces se ha considerado también como parte de la PEA informal al servicio doméstico], y la formal por todos los trabajadores no agrícolas que no son considerados informales.
}

CUADRO 4

América Latina: Segmentación de la fuerza de trabajo, 1950-1980a

(Porcentajes sobre el total de los ocupados)

\begin{tabular}{lcccccc}
\hline & \multicolumn{2}{c}{1950} & & \multicolumn{2}{c}{1980} \\
\cline { 2 - 3 } \cline { 5 - 6 } & Agrícola & No agrícola & & Agrícola & No agrícola \\
\hline Informal/tradicional & 32,6 & 13,5 & & 18,9 & 19,4 \\
Formal/moderno & 22,1 & 30,6 & & 13,2 & 47,7 \\
\hline & $54,7 \%$ & $44,1 \%$ & & $32,1 \%$ & $67,1 \%$ \\
\hline
\end{tabular}

Fuente: Tokman y García (1981 y 1984); García (1982).

a La fuerza de trabajo en la minería no fue considerada, lo que explica la pequeña merma en el total.

CUADRO 5

América Latina: Segmentación de la fuerza de trabajo, 1950-1980

(Porcentajes sobre el total de los ocupados agrícolas y no agrícolas)

\begin{tabular}{lrrrrrr}
\hline & \multicolumn{2}{c}{1950} & & \multicolumn{2}{c}{1980} \\
\cline { 2 - 3 } \cline { 5 - 6 } \cline { 5 - 6 } & Agrícola & No agrícola & & Agrícola & No agrícola \\
\hline Informal/tradicional & 59,5 & 30,6 & & 58,8 & 28,9 \\
Formal/moderno & 40,5 & 69,4 & & 41,2 & 71,1 \\
\hline & $100 \%$ & $100 \%$ & & $100 \%$ & $100 \%$ \\
\hline
\end{tabular}

Fuente: Tokman y García (1981 y 1984); García (1982).

mal se produjo un fenómeno semejante al ya apuntado para la agrícola, pues se redujo muy poco la porción informal. En 1950 ésta era el 30,6\% del total de la fuerza de trabajo no agrícola y en 1980 era todavía el 28,9\% (cuadro 5).

d) Entonces, es correcto concluir que el subempleo ${ }^{11}$ se mantuvo constante durante esos decenios, tanto en la fuerza de trabajo agrícola como en la no agrícola, cuando se las examina por separado. Pero si se considera el conjunto de subempleados —agrícolas y no agrícolas - se observa que como proporción de la fuerza de trabajo total el subempleo disminuyó de $46,1 \%$ en 1950 a $38,3 \%$ en 1980 . Esto supone que el medio urbano fue capaz de absorber la migración ruralurbana sin aumentar la proporción del sector informal, que es significativamente menor que la proporción del sector tradicional en el agro, con lo cual mejoraron los promedios nacionales.

e) Otra conclusión que surge de lo anterior es el aumento relativo del subempleo no agrícola como

\footnotetext{
${ }^{11}$ Véase una definición del subempleo utilizada en esos estudios en PREALC (1982).
} 


\begin{tabular}{|c|c|c|c|c|c|c|}
\hline & \multicolumn{2}{|c|}{1950} & & \multicolumn{2}{|c|}{1980} & \\
\hline & Agrícola & No agrícola & & Agrícola & $\overline{\text { No agrícola }}$ & \\
\hline Informal/tradicional & 70,7 & 29,3 & $100 \%$ & 49,4 & 50,6 & $100 \%$ \\
\hline Formal/moderno & 42,0 & 58,0 & $100 \%$ & 21,7 & 78,3 & $100 \%$ \\
\hline
\end{tabular}

Fuente: Tokman y García (1981 y 1984); García (1982).

consecuencia del incremento relativo de la fuerza de trabajo no agrícola y de la mencionada estabilidad de las proporciones de subempleo. En efecto, si en 1950 el 29,3\% del total del subempleo era no agrícola, en 1980 dicha proporción se había elevado a 50,6\% (cuadro 6).

En suma, el único dato positivo respecto a la evolución del subempleo durante esos treinta años es la reducción de ocho puntos porcentuales que se produjo en el conjunto de la fuerza de trabajo. Dicha reducción, sin embargo, tuvo lugar junto a un aumento considerable del número absoluto de subempleados, provocado por el fuerte ritmo de crecimiento de la fuerza de trabajo y la creciente tasa de participación, y a una mucho mayor visibilidad de los afectados debido a su mayor presencia urbana.

Sin embargo, a juicio del PREALC, la evolución insatisfactoria del subempleo no se debió a que la fuerza de trabajo no agrícola formal no hubiese crecido; al contrario, lo hizo a una tasa de $4,1 \%$ anual, superior incluso a la de la fuerza de trabajo no agrícola. Si aquella no pudo reducir el subempleo en un grado mayor fue porque en 1950 constituía una proporción pequeña en la mayoría de los países de América Latina y a que la fuerza de trabajo no agrícola creció a gran velocidad. De todas maneras, la porción formal de la fuerza de trabajo no agrícola se expandió de manera notoria en el conjunto de la fuerza de trabajo; de abarcar el 30,6\% en 1950 pasó al 47,7\% en 1980. Estas cifras le permiten al PREALC afirmar que en América Latina existió durante aquellos años, junto a la persistencia del subempleo, una transferencia significativa de fuerza de trabajo desde sectores de menor productividad hacia otros de productividad mayor. Por lo que le resulta válido concluir que el sector formal -o urbano moderno- de la economía tuvo una gran capacidad de absorción productiva.

En los estudios citados, el PREALC examina las posibles causas de estos procesos y sugiere algunas de las medidas que podrían aplicarse para reducir el subempleo, basándose para ello en la tradición de pensamiento de la CEPAL; pese al interés que despiertan esos aspectos, su análisis desborda los límites de este artículo. La evaluación del PREALC presenta también algunas debilidades metodológicas. ${ }^{12}$ De todos modos, su evaluación del proceso global de absorción productiva brinda una imagen más equilibrada de lo que sucedió entre 1950 y 1980 en este campo.

\section{III}

\section{Los cambios en la estratificación ocupacional en 1950-1980}

Si era correcto afirmar que en las décadas posteriores a 1950 se había producido un importante proceso de

\footnotetext{
${ }^{12}$ En particular, las definiciones operacionales que el PREALC utilizó para distinguir entre el segmento formal y el informal y entre el segmento moderno y el tradicional de la fuerza de trabajo pueden haber subestimado la magnitud del subempleo y, a la inversa, so-
}

brestimado la capacidad de absorción del sector formal moderno en las décadas analizadas, principalmente porque consideraron que todos los asalariados — salvo el servicio doméstico — formaban parte de este último. Seguramente una porción de los asalariados estaba en las condiciones que el PREALC atribuía al subempleo, es decir, trabajaba en actividades caracterizadas por un bajo grado de organización, escasa o nula capacidad de acumulación y una precaria inserción en el aparato productivo. 
absorción productiva de fuerza de trabajo, cabe suponer que éste tuvo un impacto considerable en la estratificación ocupacional, con los efectos consiguientes sobre la estratificación social en general. Antes de pasar revista a las investigaciones realizadas en la CEPAL sobre estos temas, cabe hacer una consideración metodológica en torno a la estratificación y la movilidad sociales.

\section{Criterios usados en la definición de los estra- tos ocupacionales}

En los estudios de estratificación ocupacional suelen utilizarse diversas variables para conformar los grandes grupos ocupacionales (estratos). Entre las variables más importantes destacan la relación con los medios productivos (que da lugar a las categorías básicas de propietarios o empleadores, diferenciados a su vez por tamaño de la empresa, y de asalariados e independientes); la naturaleza del trabajo (no manual y manual); el nivel de calificación (generalmente dividido en tres niveles, alto, medio y bajo); el grado de autoridad ejercido en la empresa (generalmente dividido también en tres niveles); el tipo de contrato (de servicio, intermedio y de trabajo, según la clasificación de Goldthorpe); $\mathrm{y}$, finalmente, las ramas y los sectores de actividad. Sobre la base de algunas de estas variables se han construido las clasificaciones de los estratos en la gran mayoría de los estudios empíricos realizados en torno a este tema, aunque el menor o mayor énfasis en algunas de ellas depende de la orientación teórica implícita o explícita de quienes realizan los estudios. Por ejemplo, las clasificaciones de ocupaciones utilizadas por organismos oficiales como el Registrar General en Gran Bretaña - la primera de las cuales data de 1911 - prestan una atención especial a los niveles de calificación y de autoridad y a la naturaleza del trabajo realizado; las de los neomarxistas, como Wright, hacen hincapié en la propiedad de los medios productivos pero no desestiman los niveles de calificación y autoridad; mientras que los neoweberianos, como Goldthorpe, consideran la relación con los medios productivos y también los niveles de calificación y autoridad, la separación en ramas agrícolas y no agrícolas y, en especial, la naturaleza del contrato (a partir de este último criterio Goldthorpe estableció su conocida división entre las clases de servicio, intermedia y trabajadora). Por supuesto, en la configuración de los estratos que se utilice tiene también particular importancia el universo al cual se aplicará el estudio - por ejemplo, por obvias razones, los estudios llevados a cabo en los países desarrollados prestan mucho menor atención a las ocupaciones agrícolas que los realizados en América Latina- y si dicho estudio utilizará datos de primera mano o extraídos de censos o encuestas de hogares. Cuando, como sucede en los estudios de la CEPAL, se utiliza información preparada para otros fines, debe tenerse presente la base de la categorización utilizada en el estudio original, la que puede ser modificada o adaptada, pero sin transgredir las posibilidades que da la recopilación estadística original.

De los criterios mencionados parte la categorización de estratos utilizada en el Panorama social de América Latina 1999-2000 (CEPAL, 2000), que se explica enseguida y que es la siguiente:

I. Empleadores, divididos por tamaño en microempleadores (hasta cuatro o cinco empleados, según los países), pequeños empleadores (de cuatro o cinco empleados a nueve o diez) y medianos y grandes empleadores (diez u once empleados y más).

II. Altos funcionarios, gerentes y directivos.

III. Profesionales de alta calificación.

IV. Profesionales de nivel intermedio, técnicos y supervisores.

V. Empleados administrativos o de oficina.

VI. Trabajadores en el comercio.

VII. Obreros, artesanos, operarios y conductores.

VIII.Trabajadores en los servicios personales y de seguridad.

IX. Trabajadores agrícolas.

En general, estos son los estratos ocupacionales que se utilizan habitualmente en las clasificaciones de las encuestas de hogares, pero en algunos casos hubo que adecuar la información a esta clasificación, para que fueran comparables los datos de ocho países en 1989-1990 y de once en 1999-2000.

Los nueve estratos enumerados constituyen la categorización básica a partir de la cual se examina la estratificación ocupacional pero, en la medida en que la información lo permite, se utilizan variables adicionales que brindan una visión más detallada de cada uno de ellos. Esto es de especial importancia porque los estratos son grandes conglomerados de ocupaciones y aunque tienen una homogeneidad básica, en su interior pueden distinguirse subestratos según el nivel de calificación, el tamaño de la empresa en que se trabaja, si se es asalariado o independiente, si la empresa es pública o privada, etc. Finalmente, los estratos -y, cuando es posible, los subestratos- se estudian y comparan a partir de tres variables principales: su proporción en la fuerza de trabajo, el ingreso ocupacional 
medio de cada uno de ellos medido en múltiplos de líneas de pobreza, y el promedio de años de estudio.

Basándose en la jerarquía de los estratos derivada del acceso al patrimonio, a niveles de mando elevados o al nivel educacional, se calificó como altos a los estratos I a III, como medios a los estratos IV y V, y como bajos a los cuatro restantes (VI a IX). Cabe destacar que los estratos altos y medios corresponden a actividades no manuales, en tanto que los estratos bajos a actividades no manuales y manuales.

Como se verá, en los primeros estudios preparados en la CEPAL se utilizaron criterios que se apartan en alguna medida de la estratificación presentada, debiéndose esto en buena parte a dudas en torno al valor clasificatorio del carácter manual y no manual de las ocupaciones. En el trabajo de Filgueira y Geneletti (1981) se utilizó la categorización de estratos recién presentada. En CEPAL (2000) se recogen las enseñanzas de los estudios previos, tanto en metodología como en un conocimiento más cabal de la naturaleza de las ocupaciones urbanas.

\section{La evaluación de comienzos del decenio de 1980}

Con el fin de examinar los efectos de la absorción productiva sobre la estratificación y movilidad sociales, a principios de la década de 1980 se realizó en la CEPAL un estudio (Filgueira y Geneletti, 1981) cuyos autores concluyeron que entre 1950 y 1970, a impulsos del dinamismo económico y demográfico, se produjeron grandes transformaciones en la composición de la fuerza de trabajo que dieron lugar a un masivo proceso de movilidad estructural ascendente. Este proceso, que por su magnitud modificó la estructura de estratificación en la mayoría de los países latinoamericanos, habría tenido sus expresiones más destacadas en la transferencia de fuerza de trabajo de las actividades agrícolas a las no agrícolas y, dentro de estas últimas, en la expansión de las ocupaciones no manua-

\footnotetext{
${ }^{13}$ La movilidad estructural es aquella que se produce por las modificaciones que los cambios técnicos y económicos generan en el tamaño absoluto y relativo de los estratos ocupacionales y en el contenido de las ocupaciones. En la terminología de la CEPAL, es el tipo de movilidad producida como consecuencia de la absorción productiva de fuerza de trabajo. La movilidad de este tipo debe ser diferenciada de otras como: la individual pura, que se produce como consecuencia del intercambio de personas entre posiciones sociales por el cual unas ascienden y otras descienden en una especie de suma cero de posiciones; la demográfica, que es el resultado de que los estratos medios y altos no tengan una tasa de fecundidad suficiente como para ocupar las posiciones correspondientes a su nivel, lo que facilita el acceso a ellas de estratos inferiores con una tasa
}

les. ${ }^{13}$ Utilizando datos de los censos de población de 1950, 1960 y 1970, los autores dividen a la fuerza de trabajo según esté ocupada en los sectores primario, secundario y terciario $\mathrm{y}$, dentro de cada uno de esos sectores, establecen dos estratos, el inferior y el medio-superior. La diferencia entre ambos estratos se basa en el carácter manual o no manual de las actividades realizadas; todos los que tienen ocupaciones no manuales pertenecen a los estratos medios y altos, y los que tienen ocupaciones manuales a los inferiores. ${ }^{14}$

Ante todo, en el presente trabajo se presentan en mayor detalle los datos que el estudio citado entrega a nivel agregado, considerando dos sectores (agrícola y no agrícola) y dos estratos ocupacionales (inferior y medio-superior). ${ }^{15}$ Así agrupados, y teniendo en cuenta los promedios simples correspondientes a los trece países para los cuales los autores presentan información del período 1950-1970, se observa que la proporción de la fuerza de trabajo ocupada en el sector primario bajó de $54,9 \%$ en 1950 a $46,9 \%$ en 1970 , lo que implica un $8 \%$ de disminución en esos 20 años debido casi en su totalidad a la reducción de los estratos inferiores de ese sector. A su vez, el aumento de la fuerza de trabajo no agrícola se debió al crecimiento de los estratos medios y altos, ya que los inferiores mantuvieron su proporción casi inalterada. En otras palabras, la disminución relativa de la fuerza de trabajo agrícola tuvo como contrapartida el incremento de los estratos medios y superiores de la fuerza laboral no agrícola en una proporción casi similar, lo que pondría de manifiesto la movilidad estructural que existió durante esos años. Pero los autores no subrayan otro hecho de gran importancia que emerge de los mismos datos: los estratos inferiores seguían siendo una mayoría abrumadora, ya que de

de fecundidad más alta; y la generada por movimientos migratorios. En América Latina todos los tipos de movilidad han tenido su importancia y a menudo se encuentran tan entremezclados que es difícil determinar con precisión el impacto de cada uno por separado.

${ }^{14}$ Los autores hacen otras diferenciaciones dentro de los estratos, a las cuales se hará referencia más adelante.

${ }^{15}$ En el análisis realizado en este artículo, a la fuerza de trabajo ocupada en el sector primario se le sumó la que no tenía ocupación especificada. Este procedimiento se justifica porque en la gran mayoría de los censos realizados en 1950 no existe fuerza de trabajo así catalogada, mientras sí existe en los posteriores; fuertes caídas en la fuerza de trabajo ocupada en la agricultura suelen corresponder con proporciones muy altas de personas sin ocupación específica. Por ejemplo, la fuerza de trabajo clasificada como agrícola en Colombia se redujo de 46,6\% en 1950 a $25,7 \%$ en 1970, mientras que la de ocupación no especificada aumentó en ese lapso en $16,1 \%$. Por cierto, usar este procedimiento puede sobrestimar la fuerza de trabajo en el sector primario, y el no utilizarlo la subestima; observando el conjunto de los datos se llegó a la conclusión de que la distorsión sería menor si se le utilizara. 
84,4\% del total de la fuerza de trabajo en 1950 sólo se redujeron a 77,4\% en 1970 (cuadro 7).

Aquí se pone de manifiesto otra vez el problema de la perspectiva con que se miran estos fenómenos; si se concentra la atención en lo que sucede en la parte media y alta de la estructura de estratificación ocupacional sobresale el crecimiento relativo de los estratos no manuales, pero si se enfoca la parte baja de esa estructura se comprueba que todavía en 1970 tres de cada cuatro miembros de la fuerza de trabajo estaban situados en los estratos inferiores.

En términos generales, utilizando esta categorización, la estratificación ocupacional media en América Latina tenía en 1970 un $44 \%$ de trabajadores manuales agrícolas, un $33 \%$ de trabajadores manuales no agrícolas y un $23 \%$ de estratos medios y superiores pertenecientes a ambos sectores, agrícolas y no agrícolas. Por cierto, esta estructura media presentaba grandes variaciones en los diferentes países. A grandes rasgos, Argentina y Uruguay tenían una estructura con proporciones del tipo 20-40-40, México de 45-30-25, Brasil de 50-30-20 y Guatemala de 60-30-10.

Dentro de la fuerza de trabajo ocupada en los sectores no agrícolas el estudio señala algunos procesos importantes. Examinando los estratos inferiores según pertenezcan a los sectores secundario y terciario, se encuentra que los estratos inferiores del sector secundario aumentaron de manera absoluta en la mayoría de los países, pero decrecieron en términos relativos en nueve de los trece países para los que se presenta información. El promedio simple de los trece países disminuyó de $25 \%$ en 1950 a $24 \%$ en 1970 . Se observó por cierto grandes diferencias entre países ya que, en general, cuanto más avanzado era el proceso de industrialización al inicio del período examinado, menor fue el crecimiento de la fuerza de trabajo de los estratos inferiores del sector secundario.

Los estratos inferiores del sector terciario crecieron más que los estratos inferiores del sector secunda-

CUADRO 7

América Latina: Dinámica de la fuerza de trabajo, 1950-1970

(Porcentajes sobre el total)

\begin{tabular}{lrrrrrr}
\hline Ocupaciones & \multicolumn{2}{c}{1950} & & \multicolumn{2}{c}{1970} \\
\cline { 2 - 3 } \cline { 5 - 6 } \cline { 5 - 6 } & \multicolumn{2}{c}{ Fuerza de trabajo } & & \multicolumn{2}{c}{ Fuerza de trabajo } \\
\cline { 2 - 3 } Agrícola & No agrícola & & Agrícola & No agrícola \\
\hline \multirow{2}{*}{ De nivel superior } & 2,9 & 12,7 & & 2,6 & 20,0 \\
De nivel inferior & 52,0 & 32,4 & & 44,3 & 33,1 \\
\hline
\end{tabular}

Fuente: Elaborado con datos de Filgueira y Geneletti (1981). rio, ya que aumentaron su proporción en ocho de los trece países; el promedio simple de los trece países pasó de 7,4\% en 1950 a 9,1\% en 1970. El decrecimiento de dichos estratos en el sector secundario y el aumento de ellos en el sector terciario dejó un modesto ascenso relativo de $0,7 \%$. Vemos así que no crecieron los del sector secundario, como Prebisch y Pinto hubieran deseado, ni tampoco en montos significativos los del terciario, como ellos temían. Lo que sucedió, como se dijo, es que aumentaron las ocupaciones no manuales en ambos sectores.

En efecto, así ocurrió en los trece países, llevando la proporción de no manuales en el total de la fuerza de trabajo de $12,7 \%$ en 1950 a $20,0 \%$ en 1970 . Este hecho lleva a los autores del estudio a afirmar que la estructura ocupacional habría sido mucho más permeable de lo que se suponía. "La movilidad estructural y ...la movilidad demográfica parecen asegurar así cierta estabilidad que impide una expansión violenta de ocupaciones bajas en el sector terciario o semimarginales del sector secundario, y que contribuye a disminuir los problemas de absorción ocupacional de los contingentes migratorios llegados de las zonas rurales" (Filgueira y Geneletti, 1981, p. 50).

Los estratos son divididos en varios niveles a fin de determinar la evolución que tuvo cada uno de ellos: el alto abarca a los empleadores y los directores y gerentes; el intermedio a los profesionales y técnicos; y el bajo a los ocupados por cuenta propia en el comercio y los asalariados de menor nivel que trabajan como empleados administrativos o están empleados en el comercio. Considerando siempre los promedios simples de los trece países se advierte que el nivel alto incrementó su proporción en menos de 1\%, lo que se debió al aumento de los gerentes y directores ya que la proporción de los empleadores se redujo levemente. Los profesionales y técnicos muestran un alza de casi $2 \%$ debido al crecimiento de los que trabajan en condición de asalariados, ya que los que lo hacen de manera independiente mantienen estable su proporción. En el nivel bajo, la proporción sube en más de $4 \%$, debido en especial al incremento de los empleados administrativos y vendedores de comercio. O sea, fueron los asalariados de los niveles alto e intermedio pero, sobre todo, los asalariados e independientes del inferior, los que alimentaron el crecimiento de las ocupaciones de los estratos no manuales urbanos.

Los autores del estudio advierten que estos diferentes niveles de las ocupaciones no manuales no sólo han tenido diferentes ritmos de crecimiento sino que también son muy heterogéneos, a tal punto que se preguntan si es correcto considerar que todos ellos perte- 
necen al mismo estrato. Someten la clasificación a una prueba basada en el ingreso y educación de los ocupados, suponiendo que no puede existir una brecha demasiado grande entre el prestigio y jerarquía de las ocupaciones, la educación de quienes las ejercen y su ingreso. En efecto, aunque no disponen de mucha información, señalan que parece existir una considerable disparidad de ingresos entre el nivel inferior y el resto, a tal punto que sostienen que se habría producido una "proletarización" del mismo. Los ingresos ocupacionales medios de este grupo se parecen mucho más a los de los trabajadores manuales que a los niveles intermedio y superior de los no manuales. Por otro lado, al contrario de lo sucedido con la distribución del ingreso, la de la educación ha sido bastante más equitativa, ya que no existen diferencias apreciables entre los diferentes niveles de las ocupaciones medias y altas, salvo en el caso de los profesionales, que tienen un nivel educacional bastante más elevado que el resto. El desarrollo educacional ha producido un acercamiento de los niveles de educación tanto dentro de los estratos ocupacionales como entre ellos, aunque se mantiene una clara brecha entre los no manuales superiores y los manuales inferiores. Examinando estas diferencias, se comprueba que para quienes tienen ocupaciones no manuales de mayor nivel es alta la coherencia entre el prestigio de sus ocupaciones, el ingreso que ellas les brindan y su nivel educacional; lo mismo sucede con los que tienen ocupaciones manuales (Filgueira y Geneletti, 1981). Pero los que tienen ocupaciones no manuales de bajo nivel se enfrentarían a una mayor incoherencia, ya que su ingreso no se correspondería con el prestigio de sus ocupaciones ni su nivel educativo; estarían así en una situación ambigua, porque formarían parte de los estratos medios por sus niveles de prestigio ocupacional y educación pero tendrían un ingreso que correspondería al de los estratos inferiores. ¿Pertenecen entonces a los estratos medios o a los inferiores? Los autores tienen dudas pero terminan colocándolos en los medios, ya que suponen que por su nivel educacional tienden a adoptar pautas de conducta y estilos de vida que se asemejan más a los de éstos que a los inferiores. Como es evidente, la decisión de considerar a las ocupaciones no manuales bajas como parte de los estratos medios tuvo consecuencias muy importantes en la principal conclusión del estudio, a saber, que entre 1950 y 1970 se produjo una considerable expansión de los estratos medios en América Latina. Si hubieran decidido considerarlos como parte de los estratos inferiores debido a su nivel de ingreso, muy distinta habría sido su conclusión sobre la evolución de la estructura de estratificación ocupacional en esos años. Quizás lo más apropiado habría sido no suponer que, por definición, todas las ocupaciones no manuales pertenecerían a los estratos sociales medios y superiores y todas las manuales a los inferiores. De ese modo podrían haber tenido más libertad para explorar las consecuencias que sobre la estratificación social estaban teniendo algunos fenómenos que ellos mismos percibieron, como la pérdida de capacidad de la educación para generar ingresos y la disminución de ingresos medios que afectaba a algunas ocupaciones no manuales.

\section{Evaluación efectuada a fines del decenio de 1980}

A fines del decenio indicado la CEPAL publicó otro estudio en el cual se retomaron los temas que se habían planteado en el que se acaba de reseñar, pero analizándolos en un período más extenso ya que dispuso de los datos censales de 1980 para algunos países. En ese estudio (CEPAL, 1989) se presentan análisis detallados de varios países pero, para los fines de este artículo, sólo se tomará en cuenta algunas de las conclusiones generales vinculadas directamente con la absorción productiva de fuerza de trabajo y sus efectos sobre la estructura ocupacional, en especial los relativos a la movilidad estructural.

Dicho estudio reafirma la idea de que entre 1950 y 1980, y sobre todo entre 1960 y 1980, habría existido un proceso de absorción productiva de gran magnitud que modificó la estructura ocupacional y provocó una fuerte movilidad de tipo estructural. Ese proceso habría sido impulsado por el fuerte crecimiento económico de aquellos años que elevó la oferta de empleos en sectores de mayor productividad, como la manufactura y los servicios, y propició su ocupación por fuerza de trabajo proveniente en buena medida de sectores de menor productividad. Aunque esa dinámica económica estuvo acompañada por cambios sociales, demográficos y políticos, en el estudio se considera que ella fue el eje principal en torno al cual giraron todos los demás procesos. El prisma con que el estudio examina lo sucedido en aquellos años corresponde al enfoque del desarrollo que es típico de la CEPAL, pero sus conclusiones difieren de las que presentaron Prebisch y Pinto en 1970, ya que insiste en que en aquellas décadas sí existió, y en gran escala, absorción productiva y movilidad estructural.

Con el fin de fundamentar esta aseveración se estima el grado de movilidad estructural que habría 
existido en algunos países entre 1960 y 1980, el que se obtuvo adicionando las diferencias en las proporciones de fuerza de trabajo que se produjeron en el paso de ocupaciones manuales agrícolas a manuales no agrícolas y de estas últimas a no manuales. En los países considerados, salvo Uruguay, habría existido una movilidad estructural ascendente que llegó en algunos a la espectacular cifra de $41 \%$.

Sin embargo, el procedimiento utilizado puede haber llevado a sobrestimar el grado de movilidad estructural. Ante todo, es poco probable que la transferencia de fuerza de trabajo de ocupaciones manuales agrícolas a manuales no agrícolas haya causado necesariamente una movilidad ocupacional ascendente de tipo estructural, o sea, que se haya pasado de una ocupación de menor a otra de mayor productividad. Es posible que el mero traslado del campo a la ciudad haya mejorado las condiciones de vida de muchos migrantes $\mathrm{y}$, por lo tanto, provocado un ascenso en otras dimensiones de la estratificación — debido, por ejemplo, al mejor acceso a los servicios de infraestructura, educación y salud - pero ello no siempre trae aparejada una movilidad ocupacional de tipo estructural. Esta crítica cobra mayor relevancia aún por el hecho de que en las cifras de movilidad estructural presentadas en el estudio tiene mayor peso la transferencia de mano de obra de ocupaciones manuales agrícolas a manuales no agrícolas que la de éstas a no manuales; el promedio simple de los diez países examinados indica que el paso de manual agrícola a manual no agrícola explicaría el $60 \%$ de la movilidad estructural que habría existido en el período examinado. En el aumento de la proporción de fuerza de trabajo manual no agrícola, provocado en buena medida por la emigración del campo a las ciudades, es probable que haya existido una combinación de absorción productiva con absorción espuria; ${ }^{16}$ el

\footnotetext{
16 Se utiliza el término "absorción productiva" para representar la incorporación de población económicamente activa al empleo de forma que aumente la productividad media de los ocupados, sin aumentar el desempleo abierto, y que no se produzcan simultáneamente caídas de la productividad media en ramas o agrupaciones productivas de significación. En los estudios cepalinos se ha asociado la absorción productiva fundamentalmente con el traslado de PEA desde el sector agropecuario a la zona urbana, y en especial al sector de la industria, desde ocupaciones manuales a no manuales, desde el sector informal al formal. También con la reducción de las diferencias de productividad entre los sectores o grupos ocupacionales mencionados, o al interior de sectores entre sus partes denominadas primitivas o tradicionales y las modernas. Por el contrario, se utiliza el término "absorción espuria" para representar la incorporación de PEA que haga caer la productividad media de un grupo ocupacional significativo, como fue el caso del sector informal en el decenio de 1980.
}

peso de cada una de ellas debe haber estado muy influido por el dinamismo económico alcanzado en cada país. Por ese motivo, llama la atención que los dos países que habrían tenido el más alto grado de movilidad estructural de los diez considerados, tuvieron tasas de crecimiento económico muy bajas en relación al promedio regional. Bolivia habría tenido una movilidad estructural de 37,5\% en el período 1950-1976 — de ese porcentaje casi dos tercios derivados de la transferencia de fuerza de trabajo manual agrícola a manual no agrícola - con un índice de incremento del PIB per cápita de sólo 28\% durante 1950-1980 ( el segundo más bajo de la región, que en promedio creció $120 \%$ ). Honduras tuvo una cifra de movilidad estructural de $41 \%$ entre 1961 y 1983 - 65\% producto del tipo de transferencia de fuerza de trabajo mencionada - con un incremento del PIB per cápita de $42 \%$ entre 1950 y 1980 (cuadro 8).

Ejemplos como estos hacen pensar que probablemente en ambos países una parte de la fuerza de trabajo que pasó de ocupaciones manuales agrícolas a manuales no agrícolas no haya experimentado movilidad estructural alguna. En otros países dicha movilidad debe haber sido bastante mayor debido al fuerte crecimiento económico: en Brasil, una movilidad estructural de $36 \%$ fue impulsada por un PIB per cápita que creció $250 \%$.

Como ya se ha mencionado, otra parte de la movilidad estructural se habría debido a la transferencia de fuerza de trabajo de ocupaciones manuales no agrícolas a no manuales. Sin embargo, en el mismo estudio se reafirman y amplían los reparos, que ya se habían insinuado en el anterior, con respecto al verdadero significado del aumento de la proporción de ocupaciones no manuales de nivel bajo en cuanto a absorción productiva y movilidad estructural. Si en el estudio anterior se expresaron dudas acerca de si tales ocupaciones debían ser consideradas parte de los estratos ocupacionales medios - aunque finalmente así se hizo - en éste se afirma que es más apropiado incluirlas en los inferiores porque en ellas abundan aquellas cuyos bajos niveles de calificación profesional e ingresos las alejan de las no manuales de mayor nivel y las acercan a las manuales no agrícolas. ${ }^{17} \mathrm{~A}$ fin de evaluar la evolución de los diferentes segmentos del conjunto de ocupaciones no manuales lo dividen en dos

\footnotetext{
17 Debe tomarse en consideración que en este punto se está evaluando el nivel de estratificación de las ocupaciones y no de las personas que pueden estar empleadas en ellas; el estrato social a que una persona pertenece está determinado por otras dimensiones además de la ocupación.
} 
América Latina (10 países): Movilidad estructural general, ${ }^{a}$ 1960-1980

\begin{tabular}{|c|c|c|c|c|c|c|c|c|c|c|}
\hline & $\begin{array}{l}\text { Argentina } \\
1960-80\end{array}$ & $\begin{array}{l}\text { Uruguay } \\
1963-75\end{array}$ & $\begin{array}{l}\text { Chile } \\
1960-80\end{array}$ & $\begin{array}{l}\text { Panamá } \\
1960-80\end{array}$ & $\begin{array}{c}\text { Costa Rica } \\
1960-82\end{array}$ & $\begin{array}{c}\text { Brasil } \\
1960-80\end{array}$ & $\begin{array}{c}\text { Perú } \\
1960-81\end{array}$ & $\begin{array}{l}\text { Ecuador } \\
1962-82\end{array}$ & $\begin{array}{l}\text { Honduras } \\
1961-83\end{array}$ & $\begin{array}{l}\text { Bolivia } \\
1950-76\end{array}$ \\
\hline $\begin{array}{l}\text { De manual no agrícola } \\
\text { a no manual }\end{array}$ & 3,3 & $-0,2$ & 14,0 & 16,7 & 7,5 & 12,1 & 13,2 & 13,3 & 14,1 & 13,9 \\
\hline $\begin{array}{l}\text { De manual agrícola a } \\
\text { manual no agrícola }\end{array}$ & 5,9 & $-0,9$ & 12,6 & 18,0 & 19,1 & 24,0 & 9,6 & 19,9 & 26,9 & 23,6 \\
\hline Movilidad estructural global & 9,2 & $-1,1$ & 26,6 & 28,2 & 26,6 & 36,1 & 22,8 & 33,2 & 41,0 & 37,5 \\
\hline
\end{tabular}

Fuente: CEPAL, 1989, p. 33.

a Ordenados por rango de modernización ocupacional.

niveles: uno alto, formado por los empleadores, gerentes y directores, y profesionales, y uno bajo, que abarca los trabajadores por cuenta propia en el comercio y los empleados administrativos y de comercio. A modo de simple indicación, puede señalarse que en los cinco países para los cuales se presenta información, la proporción de ocupaciones de nivel bajo de este estrato es superior a la de nivel alto; el promedio simple es de alrededor de $60 \%$ y $40 \%$, respectivamente, tanto en 1960 como en 1980. De ese 60\%, aproximadamente un $45 \%$ estaría constituido sobre todo por ocupaciones en que predominan los empleados de oficina y de comercio y el $15 \%$ restante por quienes trabajan por cuenta propia en el comercio. El estudio afirma que las primeras habrían sufrido una fuerte devaluación en cuanto a prestigio y nivel de ingreso por lo que ya no sería adecuado considerarlas parte de los estratos ocupacionales medios; serían más bien un segmento "terciarizado" de los estratos ocupacionales inferiores. Con respecto a las ocupaciones por cuenta propia en el comercio, que abarcaban la otra parte de las ocupaciones no manuales de bajo nivel, es sabido que presentan una gran diversidad, ya que incluyen desde los pequeños comerciantes establecidos — la llamada "pequeña burguesía" - hasta ocupaciones de muy baja productividad que constituyen una parte destacada del denominado sector informal.

Estas consideraciones críticas ponen en duda que la transferencia desde ocupaciones manuales no agrícolas a no manuales de nivel bajo lleve siempre aparejado un proceso de absorción productiva y movilidad estructural; sería quizá más apropiado considerarla un movimiento horizontal a un nivel bastante parecido de productividad e ingresos. Si así se hiciera, habría que disminuir el grado de movilidad estructural que el estudio considera que existió entre 1960 y 1980. Si esta disminución se uniera a la que también debiera hacerse ante la sobrestimación de la movilidad implicada en el paso desde ocupaciones manuales agrícolas a manuales no agrícolas mencionado antes, se alcanzaría una cifra más realista de los logros y debilidades de ese período en cuanto a absorción productiva y movilidad estructural.

Lo dicho también tiene importancia para la estratificación de las ocupaciones; en efecto, si se considera que las no manuales de nivel bajo forman parte del estrato ocupacional inferior, la estructura de estratificación ocupacional tendría una forma bien distinta de la que surge cuando se supone que ellas pertenecen a los estratos ocupacionales medios. Si así se hiciera, la estructura media en América Latina hacia 1980 habría estado conformada por un estrato superior de empleadores, gerentes y directores que giraría en torno al 5\%; uno intermedio de profesionales, técnicos y pequeños empresarios cuya proporción sería de $15 \%$ a $20 \%$; y uno inferior con sus tres segmentos de ocupaciones (no manuales de nivel bajo, manuales no agrícolas y manuales agrícolas), que abarcaría alrededor del $75 \%$ a $80 \%$ de la fuerza de trabajo. Es probable que desde el punto de vista de la distribución del ingreso medio por ocupación ésta sea la estructura de estratificación que mejor refleje las diferencias entonces existentes.

El estudio concluye que el proceso de absorción productiva y movilidad estructural, como realidad y expectativa, fue el mecanismo que brindó legitimidad social y política al estilo de desarrollo que predominó entre 1950 y 1980. Las grandes esperanzas de mejoramiento de las condiciones de vida que habían surgido en la inmediata posguerra habrían sido satisfechas, al menos en parte, durante esos años de fuerte crecimiento económico. Pero si éste perdía impulso, como era evidente a mediados de la década de 1980, aquel mecanismo de legitimación se debilitaría y podría sobrevenir una crisis política y social de gran envergadura. 


\section{IV}

\section{Absorción productiva y movilidad estructural, 1980-2000}

La controversia sigue abierta respecto a lo que sucedió con los procesos de absorción productiva y movilidad estructural entre 1950 y 1980 e interesa profundizar en ella, pues se trata de un aspecto decisivo para evaluar los resultados económicos y sociales del estilo de desarrollo predominante en aquellos años. Pero a partir de 1980 se abrió una nueva etapa en que la crisis y las políticas de estabilización y ajuste estructural tuvieron el efecto inesperado de dar una credibilidad mucho mayor a la imagen que Prebisch y Pinto esbozaron de la realidad latinoamericana y al camino que propusieron para transformarla.

Los análisis y estadísticas que aparecen anualmente en la publicación de la CEPAL Panorama Social de América Latina ayudan a presentar los rasgos principales de lo sucedido entre 1980 y 2000 en cuanto a absorción productiva y movilidad estructural y a construir un cuadro de la situación que puede servir de punto de partida para un análisis más detallado de los procesos involucrados. ${ }^{18}$

Entre aquellos rasgos destaca la brecha existente entre la evolución del producto interno bruto (PIB) y de la población económicamente activa, que puso en evidencia la insuficiencia de la economía para absorber de manera productiva a la fuerza de trabajo. En efecto, de 1980 a 1990 el PIB del conjunto de la región aumentó un modesto $12 \%$ al tiempo que la población económicamente activa crecía $33 \%$; en la década siguiente estas variables evolucionaron de manera un poco más favorable, ya que el PIB aumentó $33 \%$ mientras la PEA lo hacía en $30 \%$; los guarismos del PIB, más positivos que en la década anterior, fueron sin embargo extremadamente modestos y no alcanzaron a dar un signo positivo a los veinte años analizados. Estas elasticidades — producto del empleo de valores 3 y 1 - se apartan claramente de las de procesos de crecimiento, en especial la primera. El crecimiento económico señalado y la naturaleza de la transformación en marcha gestaron una insuficiencia dinámica que produjo dos efectos principales: aumentó la desocupación abierta y

${ }^{18}$ Véanse en especial los números de Panorama Social de América Latina, desde 1994 hasta 2000. favoreció o forzó el empleo en ocupaciones de baja productividad. La desocupación abierta, que era de $6 \%$ en 1980 , se elevó a $8 \%$ en 1990 y a $10 \%$ en 1999 ; en este último año varios países tenían tasas que fluctuaban entre $15 \%$ y $20 \% .{ }^{19} \mathrm{El}$ incremento del empleo en ocupaciones de baja productividad se produjo porque la fuerza de trabajo, afectada por el lento crecimiento económico, sólo pudo incorporarse a ese tipo de ocupaciones, lo que impulsó el aumento del subempleo.

Sin embargo, la explicación del lento crecimiento económico y, en parte, del rápido aumento de la población económicamente activa, se encuentra en los cambios estructurales que se produjeron en aquellos años en la mayoría de los países latinoamericanos, como fruto de procesos de ajuste seguidos de reformas y de la forma que se implementaron. Símbolo de los últimos son los procesos de apertura, privatización y liberalización, que produjeron modificaciones significativas en la estructura ocupacional, la absorción productiva y la movilidad estructural.

Se esperaba que esos procesos aumentaran de manera masiva las ocupaciones de mayor productividad, pero no sucedió así porque las empresas medianas y grandes, presionadas para aumentar su nivel de competitividad internacional debido a la apertura, tendieron a aumentar el nivel de mecanización e informatización y a expulsar mano de obra. Por tal motivo, dichas empresas, que habían sido el principal motor de la absorción productiva entre 1950 y 1980, redujeron de manera drástica esa capacidad. En los decenios de 1980 y 1990, con distintas intensidades, una buena parte de los nuevos empleos se crearon en empresas pequeñas, que tienen un nivel de productividad mucho menor que las anteriores. En esos años también continuó el proceso de aumento relativo del empleo en los sectores de comercio y servicios y el estancamiento del empleo industrial, que tanto había

\footnotetext{
19 Promedio simple de 15 países. Al evaluar el impacto económico y social de estas cifras debe tomarse en cuenta que en la mayoría de los países de la región no existe protección alguna frente al desempleo.
} 
preocupado a Prebisch y Pinto en la etapa previa de desarrollo. Hacia fines del siglo XX, la agricultura ocupaba, en promedio, a $20 \%$ de la fuerza de trabajo, la industria a $25 \%$ y los servicios a $55 \%$; nueve de cada diez empleos creados entre 1990 y 1999 lo fueron en los servicios y, de ellos, el 70\% en actividades de baja productividad (Klein y Tokman, 2000). También en diversos números del Panorama social de América Latina se subraya que los trabajadores ocupados en el sector privado que tienen menor calificación y realizan actividades de menor productividad (empleados en empresas de hasta cinco trabajadores, trabajadores domésticos y por cuenta propia y familiares no remunerados sin calificación técnica o profesional) aumentaron su proporción y vieron reducirse sus ingresos medios en la gran mayoría de los países para los que se cuenta con información relativa a los decenios de 1980 y 1990.

En esos decenios también se deterioraron las condiciones de contratación de una buena parte de los trabajadores asalariados, especialmente los ocupados a menor nivel de productividad, como resultado del debilitamiento de su poder de negociación y de la presión empresarial para "flexibilizar" los contratos con el fin de reducir el costo de la mano de obra. En consecuencia, bajaron los ingresos ocupacionales de esta parte de la fuerza de trabajo, lo que se refleja en que el salario mínimo existente en 1999 era un 25\% inferior al de 1980.

El aumento de la proporción de fuerza de trabajo ocupada con menor nivel de productividad, junto al deterioro de sus condiciones contractuales y la reducción de sus ingresos ocupacionales, contrasta con la situación de los profesionales y técnicos empleados en el sector privado. En efecto, la proporción de estos grupos también se elevó en todos los países para los que se cuenta con información, tanto en la década de 1980 como en la de 1990; y sus ingresos medios, que habían disminuido en el decenio de 1980, subieron en el de 1990, y en algunos países dicho aumento fue suficientemente alto como para que sus ingresos crecieran después de recuperar lo perdido en la década de 1980.

Sin embargo, el incremento global de los profesionales y técnicos fue afectado por la notoria disminución de la proporción de ocupados en el sector público, que se manifestó en distintos grados en todos los países a partir de 1980. La reducción del papel empleador del Estado conmovió a grupos ocupacionales de diverso nivel de calificación e ingreso, pero sobre todo a los no manuales de niveles de calificación intermedio y alto. Aunque fragmentarios, los datos disponibles ponen de manifiesto que dicha disminución, en algunos países, alcanzó magnitudes de entre 30\% y $40 \%$ de la fuerza de trabajo empleada en dicho sector. Debe tomarse en consideración que, por ejemplo, en Costa Rica, Panamá, Uruguay y Venezuela los ocupados en el sector público abarcaban en 1980 entre el $25 \%$ y el $30 \%$ de la fuerza de trabajo urbana total, lo que indica el impacto que su reducción tuvo sobre la estructura ocupacional. En general, pero sobre todo en aquellos países que a principios del decenio de 1980 exhibían una proporción importante de técnicos y profesionales empleados en el sector público, el aumento de los ocupados en el sector privado no logró compensar tal disminución. El ingreso medio de este grupo tendió a caer en la década de 1980 para aumentar en la de 1990, aunque en esta última se presentaron situaciones nacionales bastante diferentes. La impresión general que deja la información disponible es que los ingresos medios de este grupo se recuperaron a mediados de la década de 1990 y que en algunos países superaron el nivel que tenían a principios de la de 1980 . Esa tendencia tuvo algunas excepciones: por ejemplo, los trabajadores estatales de Venezuela perdieron en ese lapso el 60\% de su ingreso medio.

De todos modos, los profesionales más calificados constituyen uno de los grupos ocupacionales que mayores beneficios han podido obtener entre 1980 y 2000, ya que en especial la modernización de las empresas privadas ha aumentado la oferta de empleos bien remunerados a ese nivel; lo mismo ha sucedido en la mayoría de los países con los cuadros técnico-burocráticos estatales de alta calificación. Por lo tanto, se ha producido una considerable desigualdad entre los ingresos ocupacionales de este pequeño grupo de profesionales y directivos y el del contingente mayoritario de la fuerza de trabajo ocupado a menores niveles de productividad e ingresos. La disparidad en las remuneraciones de ambos grupos ocupacionales es una de las causas principales de la creciente desigualdad en la distribución del ingreso existente en los países de América Latina.

El período transcurrido entre 1980 y 2000 ha dejado un saldo poco alentador en cuanto a absorción productiva y movilidad estructural. Como se ha dicho, los motores que impulsaron la absorción productiva entre 1950 y 1980 redujeron su impulso de manera notoria, por lo que la gran mayoría de la fuerza de trabajo debió emplearse en ocupaciones de baja productividad e ingresos o permanecer desocupada. Sólo logró escapar a este destino la minoría formada, en especial, por los poseedores de activos productivos y los que gracias a su muy elevado nivel de calificación 
profesional pudieron obtener empleos bien remunerados en empresas modernas de alta productividad, especialmente medianas y grandes, y en la tecnocracia estatal.

Estas tendencias generales se expresan en la configuración de la estratificación ocupacional existente a fines del decenio de 1990, pues en ella se reflejan las oportunidades ocupacionales que brinda la economía. ${ }^{20}$ Tomando como base la clasificación de ocupaciones definida anteriormente, los datos permitieron examinar el ingreso ocupacional. En la cúspide del conjunto de ocupaciones está la de empresario privado mediano y grande, que abarca menos de $1 \%$ del total de la fuerza de trabajo y brinda ingresos muy superiores a cualquier otra ocupación, no inferiores a 30 líneas de pobreza. Es preciso realizar estudios más detallados para conocer cómo ha evolucionado este tipo de ocupación, pero puede afirmarse que en los países que más han avanzado en la nueva modalidad económica, como Chile, se aprecia un proceso de concentración que se ha fortalecido a costa de los pequeños empleadores, junto a un aumento apreciable de sus ingresos absolutos y relativos. El lugar en que se halla esta ocupación también pone de manifiesto que la posesión de activos productivos sigue siendo un criterio principal para determinar la posición de las ocupaciones en la estructura de estratificación.

A bastante distancia de la ocupación anterior, con un promedio de 12 líneas de pobreza de ingreso ocupacional, están las labores de director y gerente en las empresas privadas medianas y grandes y en el Estado (2\% del total de ocupados); el profesional asalariado de alto nivel que trabaja en esas organizaciones, y el que puede obtener este ingreso trabajando de manera independiente, que son cada vez menos (en total 3\%); y los empresarios de empresas pequeñas y microempresas $(4 \%)$. Tales ocupaciones se caracterizan por la propiedad de activos productivos, el desempeño de un papel importante (directivo y/o profesional) en una tecnoburocracia privada o pública, o un nivel de calificación profesional suficientemente alto como para tener éxito trabajando de manera independiente. Estas ocupaciones, junto a las de la elite de empresarios medianos y grandes, son las que otorgan a quienes las ocupan poder técnico-burocrático, alto prestigio ocupacional e ingresos mucho más elevados que al resto. Abarcan el 10\% del conjunto de ocupa-

\footnotetext{
${ }^{20}$ Los autores realizaron un estudio sobre este tema que fue publicado en Panorama social de América Latina 1999-2000 (CEPAL, 2000, cap. 2.).
}

ciones y sirven de base al estrato social dominante y privilegiado en el modelo económico neoliberal, que no se diferencia demasiado en magnitud al del modelo previo, pero sí en su situación y poder relativos.

El 90\% de ocupaciones restantes, que no han salido beneficiadas en la distribución del poder, el prestigio y el ingreso, puede ser dividido de acuerdo con los criterios de jerarquía y prestigio presentados anteriormente. Sin embargo, cabe destacar que son bastante homogéneas en su nivel de ingreso medio ocupacional, sobre todo teniendo en cuenta el ingreso de las ocupaciones superiores: los extremos de ingreso ocupacional para ese $90 \%$ de ocupaciones son 5 y 2 líneas de pobreza (cuadro 9). Constituyen así un vasto conjunto de ocupaciones de carácter muy diverso, que se distinguen por tener ingresos medios bastante parecidos y estar a una distancia muy considerable —en cuanto a poder, prestigio e ingreso- de las ocupaciones superiores.

Dicho conjunto está encabezado por las ocupaciones de empleado administrativo (8\%), profesional de menor nivel y técnico $(6 \%)$, que son ofrecidas en su mayoría por el sector privado y en menor proporción por el Estado, y reciben una remuneración media de 5 líneas de pobreza. La modernización de las empresas privadas, el achicamiento del Estado y el incremento de la oferta de mano de obra han continuado contribuyendo al deterioro que la mayoría de estas ocupaciones ya venía padeciendo desde décadas anteriores, traducido en la pérdida de estabilidad, prestigio ocupacional e ingreso de profesores, personal de salud, contadores, empleados bancarios, empleados de grandes empresas públicas o privadas, y otros. Son ocupaciones que exigen un nivel educativo bastante alto, que se asemeja al de las ocupaciones superiores, pero brindan salarios que son bastante parecidos a los de las ocupaciones manuales. Como es evidente, el menoscabo de estas ocupaciones ha afectado mucho la situación y perspectivas de la clase media en América Latina.

La categoría de trabajador en el comercio (13\%) encierra una variedad muy grande de ocupaciones que va desde algunas que deberían situarse junto a los empleados administrativos a la de vendedor ambulante. Sin embargo, el grueso de esa categoría abarca ocupaciones de bajo nivel de calificación, que requieren un nivel educativo menor que las anteriores y obtienen un ingreso ocupacional también menor (3,6 líneas de pobreza). Aunque se trata de ocupaciones que en su mayoría son "no manuales", no cabe duda que es equivocado considerar que su incremento es una expresión de modernización de la estructura ocupacional; por 
CUADRO 9

América Latina (ocho países): Algunas características

de los estratos ocupacionales, $1997^{\mathrm{a}}$

\begin{tabular}{|c|c|c|c|}
\hline Estratos ocupacionales & $\begin{array}{l}\text { Porcentaje de la fuerza } \\
\text { de trabajo ocupada }\end{array}$ & $\begin{array}{l}\text { Ingreso medio (en líneas } \\
\text { de pobreza per cápita) }\end{array}$ & $\begin{array}{c}\text { Promedio de años } \\
\text { de estudio }\end{array}$ \\
\hline 1. Empleadores & 4,3 & 15,8 & 8,9 \\
\hline 2. Directores, gerentes & 2,0 & 11,6 & 11,5 \\
\hline 3. Profesionales & 3,1 & 12,1 & 14,9 \\
\hline $1+2+3$ & 9,4 & 13,7 & 11,4 \\
\hline 4. Técnicos & 6,0 & 5,3 & 12,1 \\
\hline 5. Empleados administrativos & 7,9 & 4,8 & 10,6 \\
\hline $4+5$ & 13,9 & 5,0 & 11,2 \\
\hline 6. Trabajadores en el comercio & 13,4 & 3,6 & 7,3 \\
\hline 7. Obreros, artesanos, conductores & 25,3 & 3,4 & 6,1 \\
\hline $6+7$ & 38,7 & 3,5 & 6,5 \\
\hline 8. Trabajadores de los servicios personales & 14,8 & 2,2 & 5,5 \\
\hline 9. Trabajadores agrícolas & 19,6 & 1,8 & 2,9 \\
\hline $8+9$ & 34,5 & 2,0 & 4,0 \\
\hline $6+7+8+9$ & 73,2 & 2,8 & 5,3 \\
\hline 10. No clasificados & 3,5 & 4,0 & 6,8 \\
\hline 11. Total & 100,0 & 4,1 & 6,8 \\
\hline
\end{tabular}

Fuente: Panorama social de América Latina 1999-2000 (CEPAL, 2000, cap. A, p. 61).

a Promedio ponderado de ocho países.

el contrario, los que trabajan en ellas suelen verse sometidos a un alto grado de inestabilidad laboral y a condiciones de explotación laboral.

Las ocupaciones de obrero, artesano, operario y conductor de medio de transporte (3,4 líneas de pobreza), que abarcan a $25 \%$ del conjunto de ocupaciones, tienen en alta proporción carácter manual y se las incluye en los estratos bajos. Su ingreso ocupacional es de 3,4 líneas de pobreza, y a este respecto, no se diferencian del de los trabajadores en el comercio. Aproximadamente la mitad de estos puestos de trabajo son ofrecidos por empresas medianas y grandes, y un cuarto corresponde a trabajo independiente; en ambos casos los ingresos ocupacionales son un poco mayores que los ofrecidos por las empresas pequeñas.

En la parte más baja de la pirámide de estratificación se encuentran las ocupaciones de trabajador de servicios personales (15\%) y trabajador agrícola (20\%), ambas con un ingreso ocupacional medio en torno a las dos líneas de pobreza.

En suma, en la estratificación ocupacional de fines del decenio de 1990 destaca el hecho de que los estratos superiores han logrado incorporarse a actividades asociadas a la porción reducida pero dinámica de las empresas que participan en los frutos de la aper- tura. La jerarquía de esas ocupaciones, el poder económico al que están asociadas y el ingreso que captan, le permiten a este $10 \%$ más alto alcanzar un nivel de vida que, en términos relativos, se diferencia de los otros estratos mucho menos que el de sus pares en los países desarrollados. Muchas ocupaciones que antes también los brindaban, constituyéndose en el soporte de la clase media, se han deteriorado de manera considerable, empujando a sus ocupantes hacia la parte baja de la pirámide de estratificación. Otras, como las de los técnicos, han logrado elevar su ingreso y su participación, compensando en parte el deterioro de otros grupos.

Como obvio resultado de este proceso, la base de la pirámide ha aumentado y en ella se mezclan ocupaciones muy diversas. A las ya definidas se suman otras que perdieron jerarquía e ingresos. A sus denominadores comunes se les agrega el de un ingreso ocupacional que no sólo es bajo en términos absolutos sino también relativos, comparado en especial con el de las ocupaciones superiores. En efecto, el tipo de estructura de estratificación ocupacional predominante en América Latina se caracteriza por la combinación de alta desigualdad y bajo ingreso medio, de manera que la gran mayoría de las ocupaciones no brinda un 
ingreso ocupacional que sea suficiente por sí solo para que una familia de cuatro miembros se sitúe por encima del umbral de la pobreza. Muchos miembros de la fuerza de trabajo han procurado salvar estas dificultades elevando su nivel educativo, pero ese esfuerzo choca con el estrechamiento de las buenas oportunidades ocupacionales, lo que debilita el papel de la educación como canal de movilidad social.

Por cierto, como ya se ha dicho, estas tendencias generales sobre lo sucedido en 1980-2000 en cuanto a absorción productiva, movilidad estructural y estratificación ocupacional deben constituir el punto de partida de estudios más acuciosos que muestren la diversidad de situaciones y trayectorias nacionales y pon- gan de manifiesto la heterogeneidad que encierran las grandes categorías ocupacionales.

Ese es el trabajo que está por delante. Sin embargo, dichas tendencias muestran que las ideas de Prebisch y Pinto acerca de la insuficiencia dinámica y la heterogeneidad estructural de las economías de América Latina siguen teniendo una gran actualidad y son útiles, con los ajustes que exige un nuevo contexto, para orientar las investigaciones futuras en este campo. Del mismo modo, también debieran ser revalorizadas sus propuestas, que sitúan en un lugar de privilegio el logro de una mayor homogeneidad productiva y de ingreso de la fuerza de trabajo, como condición irremplazable para construir sociedades más equitativas.

\section{Bibliografía}

Centro de Proyecciones Económicas (1984): La absorción productiva de la fuerza de trabajo: una polémica abierta, Revista de la CEPAL, $\mathrm{N}^{\circ}$ 24, LC/G.1324, Santiago de Chile, diciembre.

CEPAL (Comisión Económica para América Latina y el Caribe) (1989): Transformación ocupacional y crisis social en América Lati$n a$, Libros de la CEPAL, $\mathrm{N}^{\circ}$ 22, LC/G.1558-P, Santiago de Chile. Publicación de las Naciones Unidas, $\mathrm{N}^{\circ}$ de venta: S.90.II.G.3. (2000): Panorama social de América Latina, 1999-2000, LC/G.2068-P, Santiago de Chile. Publicación de las Naciones Unidas, $\mathrm{N}^{\mathrm{o}}$ de venta: S.00.II.G.18.

Filgueira, Carlos y Carlo Geneletti (1981): Estratificación y movilidad ocupacional en América Latina, serie Cuadernos de la CEPAL, No 39, E/CEPAL/G.1122, Santiago de Chile.

García, Norberto (1982): Absorción creciente con subempleo persistente, Revista de la CEPAL, No 18, E/CEPAL/G.1221, Santiago de Chile, diciembre.

Gurrieri, Adolfo (comp.) (1982): Obra de Raúl Prebisch en la CEPAL, México, D.F., Fondo de Cultura Económica.

Kaztman, Rubén (1984): Las transformaciones sectoriales del empleo en América Latina, Revista de la CEPAL, $\mathrm{N}^{\circ}$ 24, LC/G.1324, Santiago de Chile, diciembre.

Klein, Emilio y Víctor Tokman (2000): La estratificación social bajo tensión en la era de la globalización, Revista de la CEPAL, $\mathrm{N}^{\mathrm{o}}$ 72, LC/G.2120-P, Santiago de Chile, diciembre.

Pinto, Aníbal (1970): Naturaleza e implicaciones de la "heterogeneidad estructural" de la América Latina en El trimestre Económico, Vol. XXXVII (145), México.
(1973): Heterogeneidad estructural y modelos de desarrollo reciente de la América Latina, Inflación: raíces estructurales, México, D.F., Fondo de Cultura Económica.

PREALC (Programa del Empleo para América Latina y el Caribe) (1982): Planificación del empleo, Santiago de Chile, PREALC, Organización Internacional del Trabajo (OIT).

Prebisch, Raúl (1949): El desarrollo económico de la América Latina y algunos de sus principales problemas, E/CN.12/89, Santiago de Chile, CEPAL.

(1950): Crecimiento, desequilibrio y disparidades: interpretación del proceso de desarrollo económico, Estudio económico de América Latina, 1949, E/CN.12/164/Rev.1, Nueva York, Naciones Unidas. Publicación de las Naciones Unidas, $\mathrm{N}^{\mathrm{o}}$ de venta: S.51.II.G.1.

(1952): Problemas teóricos y prácticos del crecimiento económico, E/CN.12/221, México, D.F., CEPAL. Publicación de las Naciones Unidas, $\mathrm{N}^{\circ}$ de venta: 52.II.G.1.

(1970): Transformación y desarrollo. La gran tarea de América Latina, México, D.F., Fondo de Cultura Económica.

Slawinski, Zygmunt (1964): La mano de obra en el desarrollo económico de América Latina en los últimos años, Santiago de Chile.

Tokman, Víctor y Norberto García (1981): Dinámica del subempleo en América Latina, serie Estudios e informes de la CEPAL, $\mathrm{N}^{\mathrm{o}}$ 10, E/CEPAL/G.1183, Santiago de Chile, CEPAL.

(1984): Transformación ocupacional y crisis, Revista de la CEPAL, $\mathrm{N}^{\circ}$ 24, LC/G.1324, Santiago de Chile, diciembre. 